\title{
A Case Study of Terrain Influences on Upscale Convective Growth of a Supercell
}

\author{
Jake P. Mulholland, ${ }^{\text {a }}$ Stephen W. Nesbitt, And Robert J. TrapP \\ Department of Atmospheric Sciences, University of Illinois at Urbana-Champaign, Urbana, Illinois
}

(Manuscript received 2 April 2019, in final form 19 July 2019)

\begin{abstract}
Satellite- and ground-based radar observations have shown that the northern half of Argentina, South America, is a region susceptible to rapid upscale growth of deep moist convection into larger organized mesoscale convective systems (MCSs). In particular, the complex terrain of the Sierras de Córdoba is hypothesized to be vital to this upscale-growth process. A canonical orographic supercell-to-MCS transition case study was analyzed to determine the influence that complex terrain had on processes governing upscale convective growth. High-resolution numerical modeling experiments were conducted in which the terrain height of the Sierras de Córdoba was systematically modified by raising or lowering the elevation of terrain above $1000 \mathrm{~m}$. The alteration of the terrain lead to both direct and indirect effects on storm morphology. A direct effect included terrain blocking of cold pools, whereas indirect effects included terrain-induced variations in pertinent storm environmental parameters (e.g., vertical wind shear, convective available potential energy). When the terrain was raised, low-level and deep-layer vertical wind shear increased, mixed-layer convective available potential energy decreased, deep moist convection initiated earlier, and cold pools were blocked and generally became stronger and deeper. The reverse occurred when the terrain was lowered, resulting in a weaker supercell that did not grow upscale into an MCS. The control simulation supercell displayed the deepest cold pool and correspondingly fastest transition from supercell to MCS, potentially revealing that the unique terrain configuration of the Sierras de Córdoba was supportive of the observed rapid upscale convective growth of this orographic supercell.
\end{abstract}

\section{Introduction}

The transition from isolated deep moist convection into larger mesoscale convective systems (MCSs; Zipser 1977), called upscale convective growth (hereafter UCG), is an important process to understand owing to the associated hazards with the respective convective modes. For example, supercells are more likely to produce tornado and large hail while MCSs are more likely to produce damaging straight-line wind gusts and flash flooding, although they are still capable of producing large hail and tornadoes (e.g., Trapp et al. 2005; Dial et al. 2010; Smith et al. 2012). This transition may also be characterized by overlapping severe weather hazards, including both tornado and flash flooding (e.g., Nielsen et al. 2015). The recommended safety procedures for tornadoes (seeking lower ground) versus flash flooding (seeking higher ground) are drastically different, which

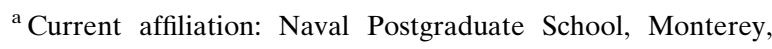
California.
}

Corresponding author: Jake P. Mulholland, jake.mulholland@ nps.edu makes these types of events especially dangerous. Additionally, numerical weather prediction models and human-driven ingredients-based approach forecasting of when storms grow upscale into MCSs have been shown to have low skill (e.g., Done et al. 2004; Hawblitzel et al. 2007; Weisman et al. 2013; Peters et al. 2017).

Previous studies on UCG, such as Coniglio et al. (2010, 2011), have found that steep low-level lapse rates, high precipitable water, large convective available potential energy (CAPE), strengthening low-level horizontal convergence at the terminus of a low-level jet (LLJ), and upper-level negative geostrophic potential vorticity (weak ambient inertial instability) all favored the most rapid transition of discrete convective cells into an MCS. Furthermore, Dial et al. (2010) found that for cases of convection initiation (CI) along a frontal or similar boundary, the potential for UCG increased when the cloud-layer wind and deep-layer vertical wind shear vectors were nearly parallel to the initiating boundary. Additionally, as the magnitude of low-level forcing increased, the potential for UCG increased.

Along with the environmental factors that may favor UCG, internal storm processes also inherently play a role in this process. Downdrafts, owing to both hydrometeor 
loading and diabatic microphysical cooling, result in the formation of cold pools beneath convective drafts. Under certain conditions, these cold pools may spread laterally and interact with neighboring cold pools, encouraging secondary CI and promoting UCG (e.g., Bluestein and Weisman 2000). Additionally, McAnelly et al. (1997) depicted that developing MCSs can generate convectively induced gravity waves that condition the surrounding environment by bolstering CAPE and reducing convective inhibition (CIN), allowing CI to occur more readily (see also Raymond 1987 and Mapes 1993). Recent idealized numerical model simulations presented by Parker (2018) showed that upscalegrowing MCSs can self-organize through both surfacebased cold pools and internal (elevated) bore processes, regardless of external influences, such as fronts or LLJs (also see Peters and Schumacher 2016).

Low-level lifting associated with the interaction between ambient low-level vertical wind shear and convective cold pools has been invoked as one idea for long-lived squall lines (Rotunno et al. 1988), although other authors have stressed the importance of upperlevel vertical wind shear on squall-line intensity (e.g., Coniglio et al. 2006). The leading edge of cold pools (hereafter "gust fronts" or "outflow boundaries") typically display increases of nonhydrostatic pressure and resultant upward-directed perturbation pressure gradient forces, inducing ascent and the potential for secondary CI (e.g., Bryan and Rotunno 2014). Furthermore, increases in low-level vertical wind shear can favor wider updrafts which may process more water vapor and result in stronger/wider downdrafts and colder cold pools (e.g., Trapp et al. 2017; Warren et al. 2017; Nielsen and Schumacher 2018; Marion and Trapp 2019). Recent idealized supercell simulations by Trapp et al. (2017) and Marion and Trapp (2019) showed that increases in vertical wind shear over the lowest $2 \mathrm{~km}$ resulted in stronger/wider updrafts and downdrafts, more precipitation production and stronger/wider cold pools. Warren et al. (2017) found similar supercell characteristics for increases in upper-level vertical wind shear $(6-12 \mathrm{~km})$. These stronger/wider cold pools in environments with increased vertical wind shear, which may initially favor supercells as the primary convective mode, may later favor a more rapid upscale transition into MCSs via cold pool amalgamation and/or surging outflows (e.g., Coniglio et al. 2010; Peters et al. 2017; and references therein).

One region of the world that is susceptible to rapid upscale growth of deep moist convection is the northern half of Argentina, South America. The present study is focused along an approximately north-south mountain chain called the Sierras de Córdoba (SDC) (e.g., Mulholland et al. 2018). Mulholland et al. (2018) analyzed 2 years of ground-based radar data from Córdoba, Argentina, and found that UCG is a common occurrence and typically happens closer to the terrain (within $25-50 \mathrm{~km}$ ) and more rapidly (within 3-4 h after CI) than in the central United States (USA) (also see Anabor et al. 2008; Rasmussen et al. 2014). Considering that much of the global population of MCSs form in the lee of terrain and account for nearly two-thirds of the annual precipitation accumulation (e.g., Laing and Fritsch 1997; Nesbitt et al. 2006; Rasmussen et al. 2016), it is vitally important to understand the processes by which these orographic systems first begin to evolve. This motivates the detailed analysis of an UCG case study from 29 November 2017 near Córdoba in which a supercell initiated over the SDC and rapidly transitioned into a bowing MCS in less than $4 \mathrm{~h}$, producing large hail, damaging straight-line wind gusts, and flooding. This process of supercell-to-bowing MCS transition has been documented before in the USA by Moller et al. (1990), Conway et al. (1996), Finley et al. (2001), Klimowski et al. (2004), among others, although not explicitly orographic supercell-to-bowing MCS transitions. Finley et al. (2001) used a numerical modeling approach to analyze a supercell-to-bowing MCS transition, determining that just prior to UCG, the low-level cold pool deepened and intensified, which resulted in a strong low-level horizontal pressure gradient force directed away from the cold pool. This caused an acceleration of the gust front and enhanced low-level lifting/new convective development along the leading edge of the outflow, resulting in a rapid transition to a bowing MCS. This study, however, lacked substantial terrain influence as it occurred over the relatively homogeneous terrain of the USA states of northeast Kansas and southwest Iowa.

An idealized modeling study of mature right-moving supercells near/over 2- and 3D terrain by Markowski and Dotzek (2011) found that terrain affects various environmental parameters that impact supercell sustenance, such as relative humidity (RH), low-level vertical wind shear and CIN. The authors ascertained that changes in the environment owing to terrain exerted a greater influence on storm longevity and morphology than internal storm changes owing to terrain. Soderholm et al. (2014) found that changes to the vertical wind profile exhibited more influence on convective evolution than thermodynamic alterations, with increases in lowlevel vertical wind shear downwind of the idealized mountain favoring supercell development. These studies were limited, however, by the fact that the terrain features were highly idealized, and did not directly address the influence of terrain on the UCG process of orographically forced supercells. 
Other authors have depicted that terrain may alter the mesoscale environment via flow blocking and channeling, resulting in changes to vertical wind shear and CAPE. Bosart et al. (2006) studied an F3 supercell tornado in Massachusetts and found that flow channeling fostered local enhancements to the low-level vertical wind shear profile, creating an environment favorable for supercell tornadogenesis. Miglietta et al. (2017) and Scheffknecht et al. (2017) showed that terrain impacted the triggering, location, intensity, and longevity of orographic supercells by way of flow perturbations that also enhanced low-level vertical wind shear. Tripoli and Cotton (1989a,b) have shown the importance of orographically induced thermal and mechanical flows in the upscale growth of a simulated, long-lived orographic MCS, and created a conceptual diagram highlighting a typical pathway of orographic UCG (Tripoli and Cotton 1989a, their Figs. 16-20). Additionally, terrain-cold pool interactions may be of importance to the UCG process near complex terrain. $\mathrm{Xu}$ et al. (2012) reported that a long-lived, nearly stationary heavy rainfall-producing MCS near Taiwan was maintained by a topographically trapped cold pool that acted to extend the necessary low-level lifting for secondary CI offshore, away from the topography (also see Bresson et al. 2012; Phadtare 2018).

The aforementioned external (environment, terrain) and internal (downdrafts, cold pools) processes that dictate how orographic deep moist convection (specifically supercells) initiates, matures, and eventually transitions upscale into MCSs is a relatively unexplored research topic over the full convective life cycle. Thus, the aim of the present study is to document and analyze the full convective life cycle of orographic CI to supercell development to UCG of the 29 November 2017 event via a high-resolution numerical modeling approach. The goal of this study is to document and quantify the effects that the complex terrain of the SDC had on the UCG process for this supercell-to-MCS transition event. It is hypothesized that the unique terrain configuration of the SDC impart large influences on UCG through both direct and indirect effects. Direct influences, such as terrain blocking cold pools and resultant deepening of cold pools, and indirect influences, such as terrain enhancements to low-level/deep-layer vertical wind shear and CAPE/CIN alterations, likely help explain the observed rapid UCG of deep moist convection in close proximity to the terrain of the SDC (e.g., Mulholland et al. 2018). The manuscript is structured in the following manner: section 2 outlines the data and methods for this research, section 3 provides a synoptic-scale and convective-environment overview of the 29 November 2017 event, and section 4 presents

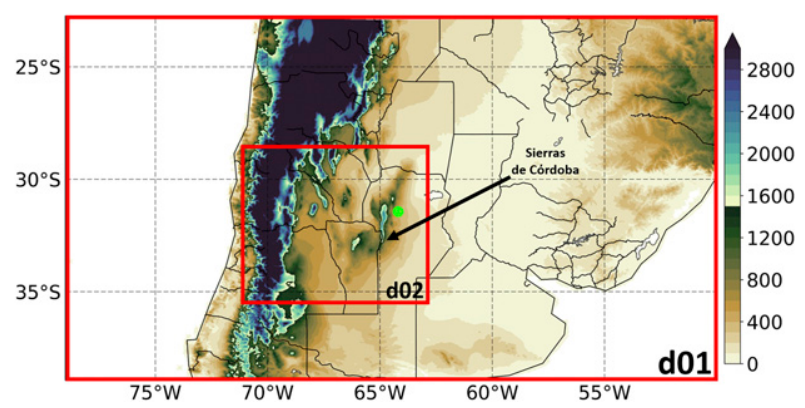

FIG. 1. Domains (red boxes) used for WRF simulations: $3 \mathrm{~km}$ grid spacing (d01) and $1 \mathrm{~km}$ grid spacing (d02). Terrain height is shaded $(\mathrm{m})$. The lime dot is Córdoba, Argentina.

results from various numerical model simulations. Summary and conclusions are given in section 5 .

\section{Data and methods}

\section{a. Observational data}

Radar reflectivity factor and Doppler radial velocity data obtained from a C-band $(5.4 \mathrm{~cm}$ wavelength) dual-polarization Doppler weather radar in Córdoba, Argentina $\left(31.42^{\circ} \mathrm{S}, 64.19^{\circ} \mathrm{W}\right.$; average elevation $\sim 450 \mathrm{~m}$ ), were used to characterize the convective morphology of this event and otherwise evaluate the accuracy of numerical model simulations described in the following sections. Additional details pertaining to the Córdoba radar specifications can be found in Mulholland et al. (2018). The 1200 UTC 29 November upper-air sounding from the Ingeniero Aeronáutico Ambrosio L.V. Taravella International Airport in Córdoba (World Meteorological Organization site code 87344) was also compared with numerical model output to verify the control simulation (hereafter CTRL-0).

\section{b. Numerical model}

The Weather Research and Forecasting (WRFARW; version 3.9.1; e.g., Skamarock et al. 2008) Model was used to simulate the 29 November event. The innermost grid for the CTRL-0 experiment had a horizontal grid spacing of $1 \mathrm{~km}(\mathrm{~d} 02 ; 751 \times 700$ grid points $)$ and was nested within a $3 \mathrm{~km}(\mathrm{~d} 01 ; 952 \times 601$ grid points) horizontal grid spacing domain (Fig. 1). It is acknowledged that at these grid spacings, convective drafts are not fully resolved (e.g., Bryan et al. 2003). An additional test CTRL-0 simulation with a horizontal grid spacing of $333 \mathrm{~m}$ was conducted, and the salient features from this higher-resolution simulation (e.g., convective mode and morphology; also see Potvin and Flora 2015 and Verrelle et al. 2015) matched those of the $1 \mathrm{~km}$ simulation. Thus, all experiments were conducted with the $3-1 \mathrm{~km}$ domain configuration. The outermost $3-\mathrm{km}$ 
TABLE 1. Summary of WRF Model specifications.

\begin{tabular}{lcl}
\hline \hline & Specification & \multicolumn{1}{c}{$\begin{array}{c}\text { Reference } \\
\text { (if necessary) }\end{array}$} \\
\hline $\begin{array}{l}\text { Horizontal grid } \\
\text { spacing }\end{array}$ & $3 \mathrm{~km}(\mathrm{~d} 01) ;$ & \\
$\begin{array}{l}\text { Vertical model levels } \\
\text { PBL scheme }\end{array}$ & 60 & \\
Microphysics & YSU & Hong et al. (2006) \\
Radiation & Thompson 7-class & Thompson et al. (2008) \\
Land surface model & RRTMG & Iacono et al. (2008) \\
& $\begin{array}{c}\text { 5-layer thermal } \\
\text { Dudhia (1996) }\end{array}$ & Dudhia \\
Cumulus scheme & None & \\
Feedback between & On & \\
nests & & \\
\hline
\end{tabular}

domain was initialized from the 0000 UTC 29 November National Centers for Environmental Prediction $0.25^{\circ}$ Global Forecast System model with lateral boundary updates every $3 \mathrm{~h}$ and was integrated forward $30 \mathrm{~h}$ until 0600 UTC 30 November with output saved every $1 \mathrm{~h}$. The $1-\mathrm{km}$ domain was introduced at 1200 UTC and was integrated forward $18 \mathrm{~h}$ until 0600 UTC 30 November with output saved every $5 \mathrm{~min}$ (every $1 \mathrm{~min}$ for $30 \mathrm{~min}$ backward parcel trajectory analyses; see details in section 3c). The model simulation had a vertically stretched grid with 60 vertical levels using a terrain-following $\sigma$ coordinate. The model top was $\sim 20 \mathrm{hPa}(\sim 26 \mathrm{~km}$ above ground level; AGL) with a $5 \mathrm{~km}$ deep absorbing layer to mitigate reflection of vertically propagating gravity/sound waves off the model top. A full listing of the model configuration and parameterization schemes can be found in Table 1 .

\section{c. Terrain experiments}

To further explore the effects of the SDC on CI, supercell formation, and UCG, four additional WRF experiments were conducted in which the terrain of the SDC was systematically varied. To isolate the SDC from surrounding mountainous regions, any terrain within the SDC range with an elevation $\geq 1000 \mathrm{~m}$ were altered for the $3-\mathrm{km}$ domain and interpolated to the 1-km domain (e.g., gray lines in Fig. 2a). The terrain was systematically varied using

$$
h=m h^{\prime}+b,
$$

where $h$ denotes the altered terrain, $h^{\prime}$ denotes the original terrain, $m=(f \times 2000-1000) /(2000-1000)$, and $b=1000-(m \times 1000)$. The scaling factor $f$ was set to $0.60,0.75,1.00,1.25$, and 1.40 , to represent terrain variations of $-40 \%$ (LOW-40), $-25 \%$ (LOW-25), $0 \%$ (CTRL-0), $+25 \%$ (HIGH-25), and $+40 \%$ (HIGH-40), respectively. An example vertical cross section through the central SDC for each of the five terrain experiments is depicted in Fig. 2. Maximum terrain height varied from $\sim 3495 \mathrm{~m}$ in the HIGH-40 experiment to $\sim 1000 \mathrm{~m}$ in the LOW-40 experiment (Fig. 2). The HIGH-40 experiment required the use of a greater vertical sound

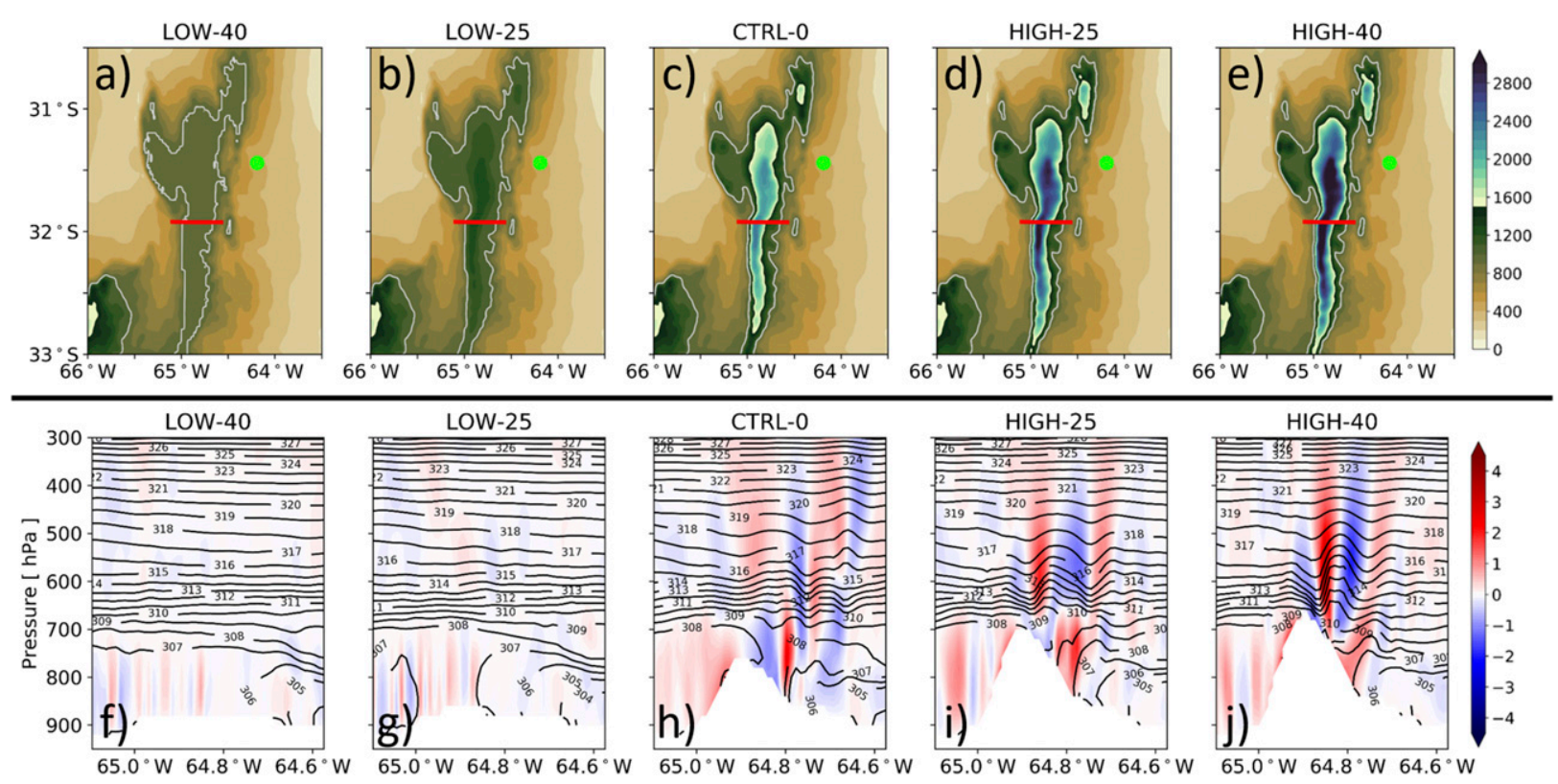

FIG. 2. $1 \mathrm{~km}$ WRF terrain height experiments: (top) plan views of terrain height (shaded; $\mathrm{m}$ ), $1000 \mathrm{~m}$ terrain height contour (gray lines), city of Córdoba (lime dot), and the location of the west-east-oriented vertical cross sections (red lines) shown in the bottom row. (bottom) Vertical cross sections of vertical velocity (shaded; $\mathrm{m} \mathrm{s}^{-1}$ ) and potential temperature (black contours every $1 \mathrm{~K}$ ) valid at 1500 UTC 29 Nov 2017. (a),(f) LOW-40, (b),(g) LOW-25, (c),(h) CTRL-0, (d),(i) HIGH-25, and (e),(j) HIGH-40 experiments. 

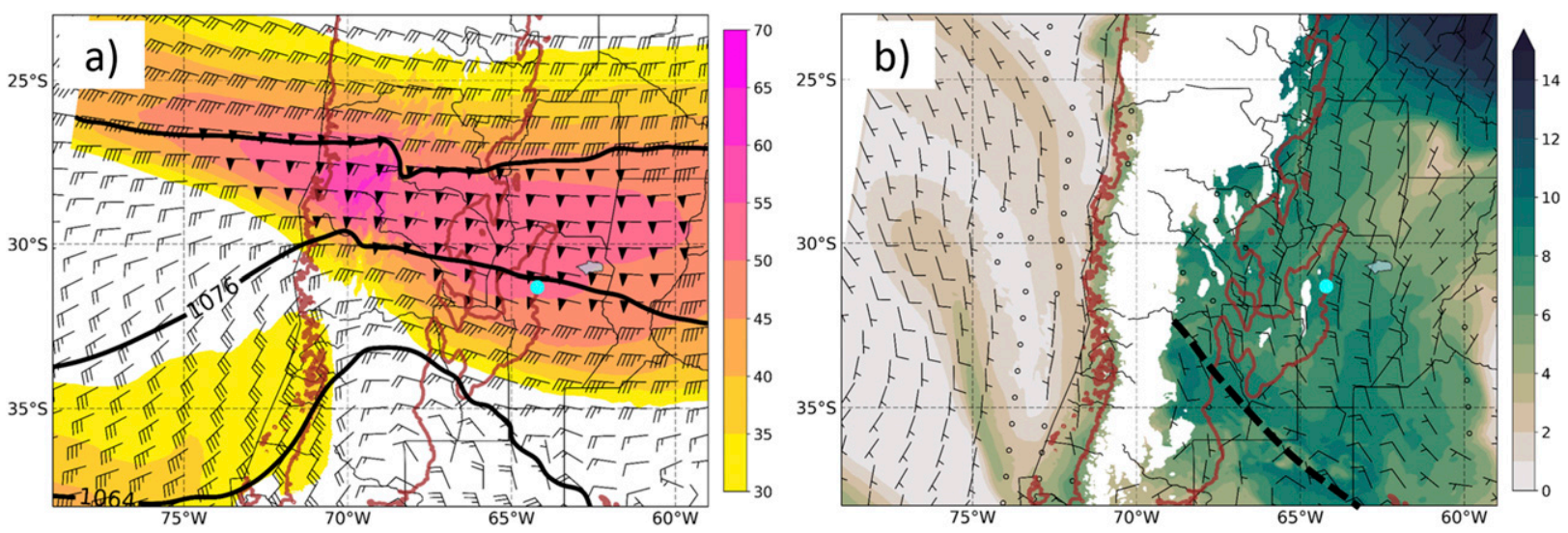

FIG. 3. 3 km CTRL-0 WRF output valid at 1200 UTC 29 Nov 2017 depicting: (a) 250 hPa isotachs (shaded; m s ${ }^{-1}$ ), geopotential height (contoured in thick black lines every $12 \mathrm{dam}$ ), horizontal winds (half barb $=5 \mathrm{~m} \mathrm{~s}^{-1}$, full barb $=10 \mathrm{~m} \mathrm{~s}^{-1}$, pennant $=50 \mathrm{~m} \mathrm{~s}^{-1}$ ), $500 \mathrm{~m}$ terrain height contour (thick brown line), and Córdoba (cyan dot). (b) $850 \mathrm{hPa}$ specific humidity ( $\mathrm{shaded} \mathrm{g} \mathrm{kg}^{-1}$ ), horizontal winds (half barb $=5 \mathrm{~m} \mathrm{~s}^{-1}$, full barb $=10 \mathrm{~m} \mathrm{~s}^{-1}$ ), $500 \mathrm{~m}$ terrain height contour (thick brown line), and Córdoba (cyan dot). The thick dashed black line in (b) is the approximate location of a convergence boundary discussed in the text.

wave propagation coefficient ( 0.5 instead of the default 0.1) to damp artificial waves. Comparisons between simulations with varying vertical sound wave propagation coefficients displayed negligible differences for pertinent atmospheric fields. All model parameterization schemes used in these additional terrain-modified simulations were consistent with the CTRL-0 simulation (see Table 1).

\section{d. Definitions}

As in Mulholland et al. (2018), CI was defined for the Córdoba radar data as the first appearance of a $\geq 30 \mathrm{~dB} Z$ echo that covered at least five range gates at the $\sim 1^{\circ}$ scan angle. Similarly, in the WRF simulations, CI was defined as the time when the lowest model level simulated radar reflectivity (covering at least one grid cell) was $\geq 30 \mathrm{~dB} Z$ and persisted $\geq 30 \mathrm{dBZ}$ for the remainder of the simulation. The supercell stage for the Córdoba radar data was subjectively determined by examining radar reflectivity for evidence of a hook echo that was accompanied by rotation (using Doppler radial velocity data) in a storm lasting $\geq 30 \mathrm{~min}$. In the WRF simulation, the peak supercell stage was defined as the time that the simulated storm obtained a minimum (i.e., largest negative) value of $2-5 \mathrm{~km}$ AGL updraft helicity (UH; Kain et al. 2008; defined as negative for the Southern Hemisphere). UCG was determined from the Córdoba radar data as the time that the length-to-width aspect ratio of the single supercell storm (contiguous $\sim 1^{\circ}$ radar reflectivity $\geq 30 \mathrm{~dB} Z$ with $\geq 50 \mathrm{~dB} Z$ embedded cores) met, or exceeded, 3:1. In the WRF simulation, UCG was defined as the time that the length-towidth aspect ratio of the simulated single supercell storm (contiguous $\geq 30 \mathrm{~dB} Z$ lowest-model level reflectivity with $\geq 50 \mathrm{~dB} Z$ embedded cores) met, or exceeded, 3:1.

Cold pools were defined using thermal buoyancy,

$$
B=g\left(\frac{\theta_{v}-\overline{\theta_{v}}}{\overline{\theta_{v}}}\right),
$$

where $g$ is gravity $\left(\mathrm{m} \mathrm{s}^{-2}\right), \theta_{v}$ is virtual potential temperature $(\mathrm{K})$, and $\overline{\theta_{v}}$ is the horizontally averaged virtual potential temperature $(\mathrm{K})$. First, model data were linearly interpolated to fixed height levels between 0 and $20 \mathrm{~km}$ AGL spaced evenly every $250 \mathrm{~m}$. For each experiment, $\overline{\theta_{v}}$ was determined from spatially averaging $\theta_{v}$ at each height level at each output time across a $50 \mathrm{~km} \times 50 \mathrm{~km}$ box located to the northeast of the upscale-growing orographic supercell (e.g., see orange dashed box in Fig. 8, top row). This region was chosen to represent the relatively flat and undisturbed (i.e., not convectively contaminated) inflowing air into the orographic supercell. The vertical depth and horizontal extent of the cold pool were characterized by regions containing $B \leq-0.1 \mathrm{~m} \mathrm{~s}^{-2}$ (e.g., Verrelle et al. 2015).

\section{Overview of the 29 November 2017 event}

\section{a. Synoptic and convective-environment overview}

The $1200 \mathrm{UTC} 250 \mathrm{hPa} 12 \mathrm{~h}$ forecast from the $3 \mathrm{~km}$ CTRL-0 simulation (which closely matched observations) depicted a $>50 \mathrm{~m} \mathrm{~s}^{-1}$ cyclonically curved jet streak with a terminus across the northern SDC (Fig. 3a). This jet streak was accompanied by an amplified upstream short-wave trough centered to the southwest of the SDC (Fig. 3a). Large-scale height falls 


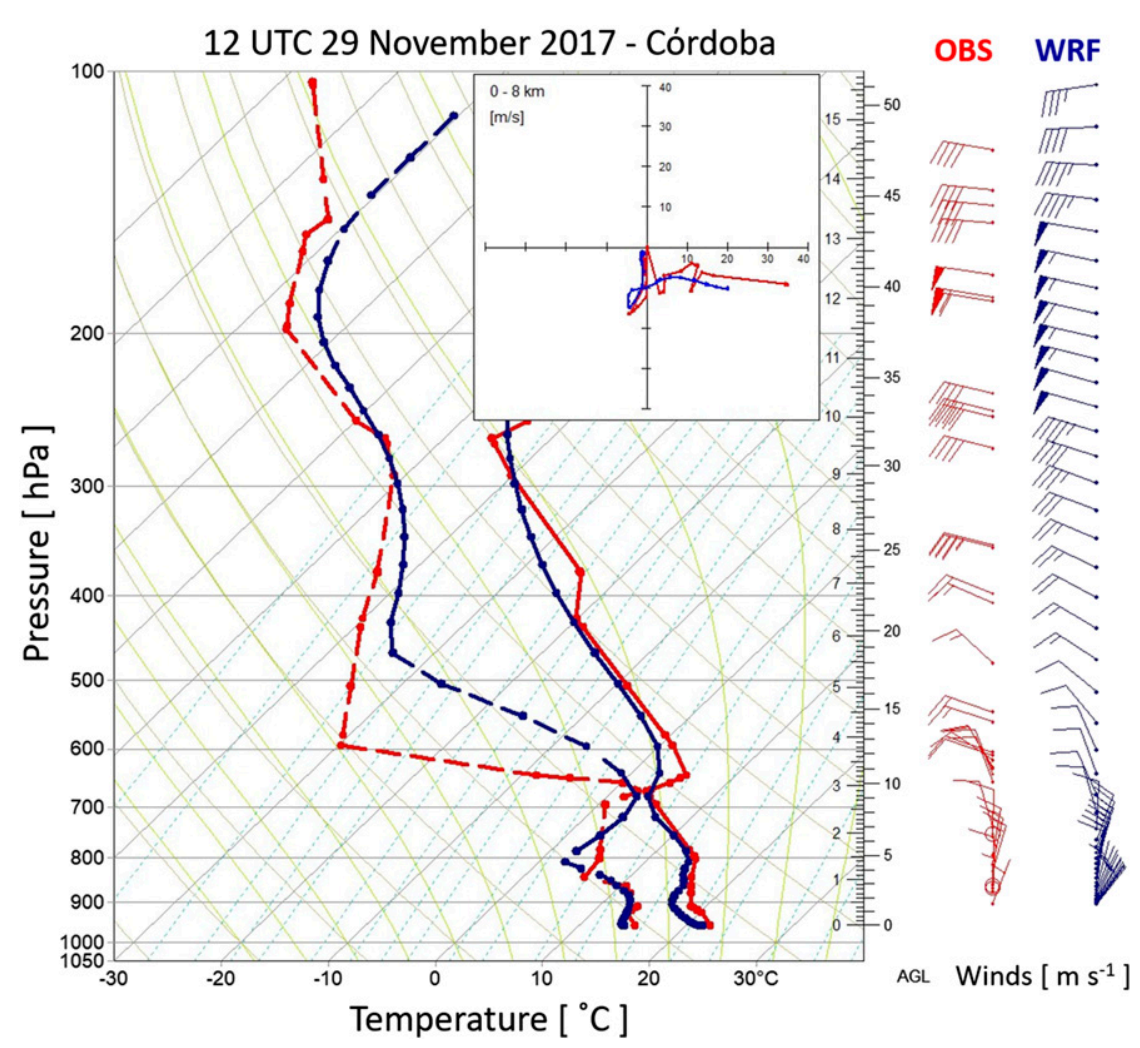

FIG. 4. 1200 UTC 29 Nov 2017 Córdoba observed (red) and 1 km CTRL-0 WRF simulated (blue) upper-air sounding plotted on a skew $T-\log p$ diagram. The rightmost solid lines are temperature $\left({ }^{\circ} \mathrm{C}\right)$ and the leftmost dashed lines are dewpoint temperature $\left({ }^{\circ} \mathrm{C}\right)$. The inset figure is the wind hodograph trace from the surface through $8 \mathrm{~km} \mathrm{AGL}\left(\mathrm{m} \mathrm{s}^{-1}\right)$. Horizontal winds are plotted on the right (half barb $=5 \mathrm{~m} \mathrm{~s}^{-1}$, full barb $=10 \mathrm{~m} \mathrm{~s}^{-1}$, pennant $=50 \mathrm{~m} \mathrm{~s}^{-1}$ ).

to the east of the upper-level trough induced low-level lee troughing across the SDC region, resulting in a northerly LLJ (commonly called the South American LLJ or SALLJ; e.g., Vera et al. 2006) with horizontal wind speeds of $\geq 10 \mathrm{~m} \mathrm{~s}^{-1}$ (Fig. 3b). As a result of the SALLJ, abundant horizontal moisture advection, with specific humidity $\geq 10 \mathrm{~g} \mathrm{~kg}^{-1}$, was commonplace across and east of the SDC (Fig. 3b). A northwest-southeast-oriented convergence boundary was located south of the SDC (thick black dashed line in Fig. 3b) which corresponded to a surface cold front (not shown). Visible satellite imagery revealed that an MCS was ongoing along the cold front at 1530 UTC south of the region with mountain waves across the southern SDC near the CI location (not shown).

The local convective environment owing to this synoptic pattern was well captured by the 1200 UTC Córdoba sounding, which depicted a near-surface air temperature and dewpoint temperature of $22^{\circ}$ and $15^{\circ} \mathrm{C}$, respectively, closely matching the model sounding from the $1 \mathrm{~km}$ CTRL-0 simulation (Fig. 4). A relatively deep moist layer extended vertically to $\sim 650 \mathrm{hPa}$, where a temperature inversion and hydrolapse (rapid change in moisture with height) were located associated with the base of an elevated mixed layer, a common feature east of the Andes Mountains (e.g., Ribeiro and Bosart 2018). This elevated mixed layer was characterized by steep midlevel lapse rates $(600-450 \mathrm{hPa}$ lapse rates of $\sim 8.2^{\circ} \mathrm{Ckm}^{-1}$ ), which contributed to early afternoon mixed-layer CAPE (MLCAPE) between $\sim 800$ and $1200 \mathrm{~J} \mathrm{~kg}^{-1}$ (Fig. 5a). The morning LLJ was also apparent in the observed and modeled soundings, evidenced by 10 $15 \mathrm{~m} \mathrm{~s}^{-1}$ horizontal wind speeds between 925 and $700 \mathrm{hPa}$ (Fig. 4). The LLJ, in combination with the upper-level jet streak, contributed to early afternoon 0-8 km AGL bulk wind difference (BWD; used hereafter as a measure of vertical wind shear) magnitudes of $\sim 25 \mathrm{~m} \mathrm{~s}^{-1}$ across the southern SDC and $\sim 35 \mathrm{~m} \mathrm{~s}^{-1}$ across the northern SDC (Fig. 5a), which was closer to the axis of the upper-level jet streak (Fig. 3a). Furthermore, a simulated point sounding downwind of the SDC at 1700 UTC depicted a $2 \mathrm{~km}$ deep, near dry adiabatic subcloud layer, steep midlevel lapse rates, minimal MLCIN, and a counterclockwise-curving (veering) low-level hodograph, with 0-2 km AGL BWD magnitudes $\sim 10-11 \mathrm{~m} \mathrm{~s}^{-1}$ (Fig. 5b). 

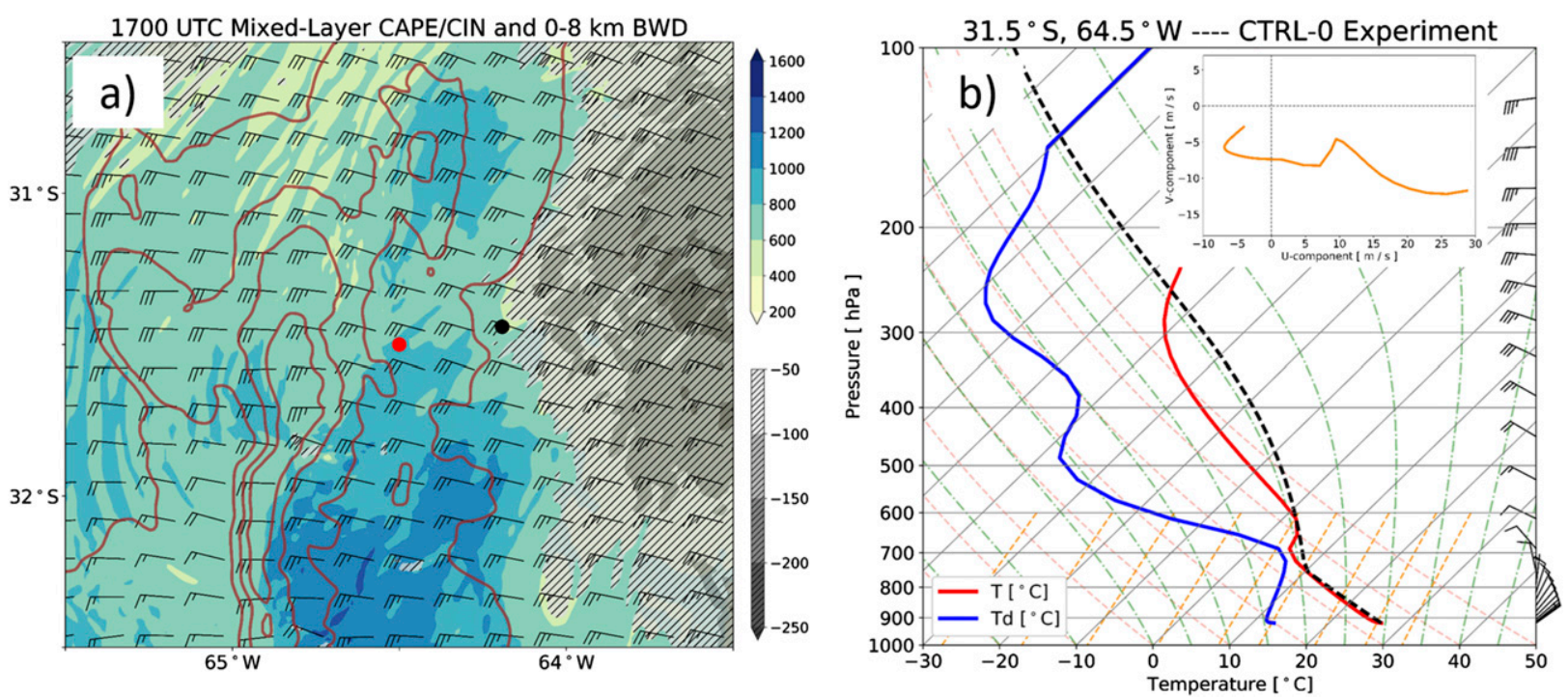

FIG. 5. 1 km CTRL-0 WRF output valid at 1700 UTC 29 Nov 2017 depicting: (a) mixed-layer CAPE (shaded; J kg ${ }^{-1}$ ), mixed-layer CIN ( shaded in gray; $\mathrm{J} \mathrm{kg}^{-1}$ ), 0-8 km AGL BWD (half barb $=5 \mathrm{~m} \mathrm{~s}^{-1}$, full barb $=10 \mathrm{~m} \mathrm{~s}^{-1}$ ), terrain height (contoured in brown every $500 \mathrm{~m}$ ), Córdoba (black dot), and the location of the model sounding (red dot). (b) Point model sounding plotted on a skew $T$-log $p$ diagram at red dot in (a). The solid red line is temperature $\left({ }^{\circ} \mathrm{C}\right)$, the solid blue line is dewpoint temperature $\left({ }^{\circ} \mathrm{C}\right)$, the dashed black line is the parcel trace for a parcel lifted from the surface, and horizontal winds (half barb $=5 \mathrm{~m} \mathrm{~s}^{-1}$, full barb $=10 \mathrm{~m} \mathrm{~s}^{-1}$ ) are plotted at the right. The inset figure in (b) is a wind hodograph trace between the lowest model level and $\sim 10 \mathrm{~km}$ AGL (orange line; $\mathrm{m} \mathrm{s}^{-1}$ ).

\section{b. Convective mode evolution}

As depicted by the Córdoba radar data, isolated deep moist convection initiated across, and just east of, the central SDC at $\sim 1742$ UTC (Fig. 6a). Given a favorable ambient environment (e.g., Fig. 5), these initial cells quickly developed into a left-moving supercell by 1914 UTC just southwest of Córdoba (Fig. 6c). Shortly thereafter, the supercell began to grow upscale, meeting the MCS criteria by 2045 UTC (Figs. 6d,e). As this system began to bow outward (to the north), it was approached and eventually overtaken to the south by the ongoing, frontal MCS (Fig. 6f).

Given the relatively deep $(\sim 2 \mathrm{~km})$ well-mixed boundary layer extending from the surface-to- $700 \mathrm{hPa}$ ("inverted-V" profile; Fig. 5b), the potential for strong downdrafts and rapid cold pool production was evident (e.g., Coniglio et al. 2010, 2011). The observed time from CI to UCG according to the Córdoba radar was $\sim 3 \mathrm{~h}$. This event was associated with social media (Twitter) reports of "orange-sized" hail, straight-line wind gusts of $\sim 20 \mathrm{~m} \mathrm{~s}^{-1}$ and flooding in/near Córdoba.

\section{Results}

\section{a. Convective mode evolution}

Compared to the radar observations, the CTRL-0 simulation accurately captured the salient features of this event (Fig. 7), particularly the location and timing of CI, supercell development, and UCG; the simulated frontal MCS was a too weak and slow, however. An analysis of the simulated low-level cold pool during the supercellto-MCS transition showed a strengthening and deepening of the cold pool, mainly along the rear-flank gust front region of the supercell (e.g., Figs. 8b,f). The cold pool was subsequently blocked by the higher terrain of the SDC to the west, leading to further deepening and eventually, northward surging outflow that paralleled the terrain. Northeasterly low-level winds blowing nearly perpendicular to the deep cold pool's gust front motion led to low-level upward vertical velocities of $2-6 \mathrm{~m} \mathrm{~s}^{-1}$ (Figs. 8f,g). This low-level ascent fostered secondary CI along the outflow boundary and a subsequent rapid growth of the supercell into a bowing MCS (Fig. 8d).

\section{b. Direct and indirect influences of terrain}

To understand the effects of the complex terrain of the SDC on this UCG process, the set of four terrain experiments described in section 2 were conducted. Recall that the maximum terrain height of the SDC was systematically varied between $\sim 3495 \mathrm{~m}$ in the HIGH-40 experiment and $\sim 1000 \mathrm{~m}$ in the LOW-40 experiment. A direct effect that the increased terrain height of the SDC had on the convective morphology was an earlier CI time and slightly different locations along the SDC (Fig. 9, top row; Table 2). In the HIGH-40 experiment, CI was $\sim 1510$ UTC, whereas in the LOW-40 experiment CI was $\sim 1750$ UTC, with CI in the CTRL-0 

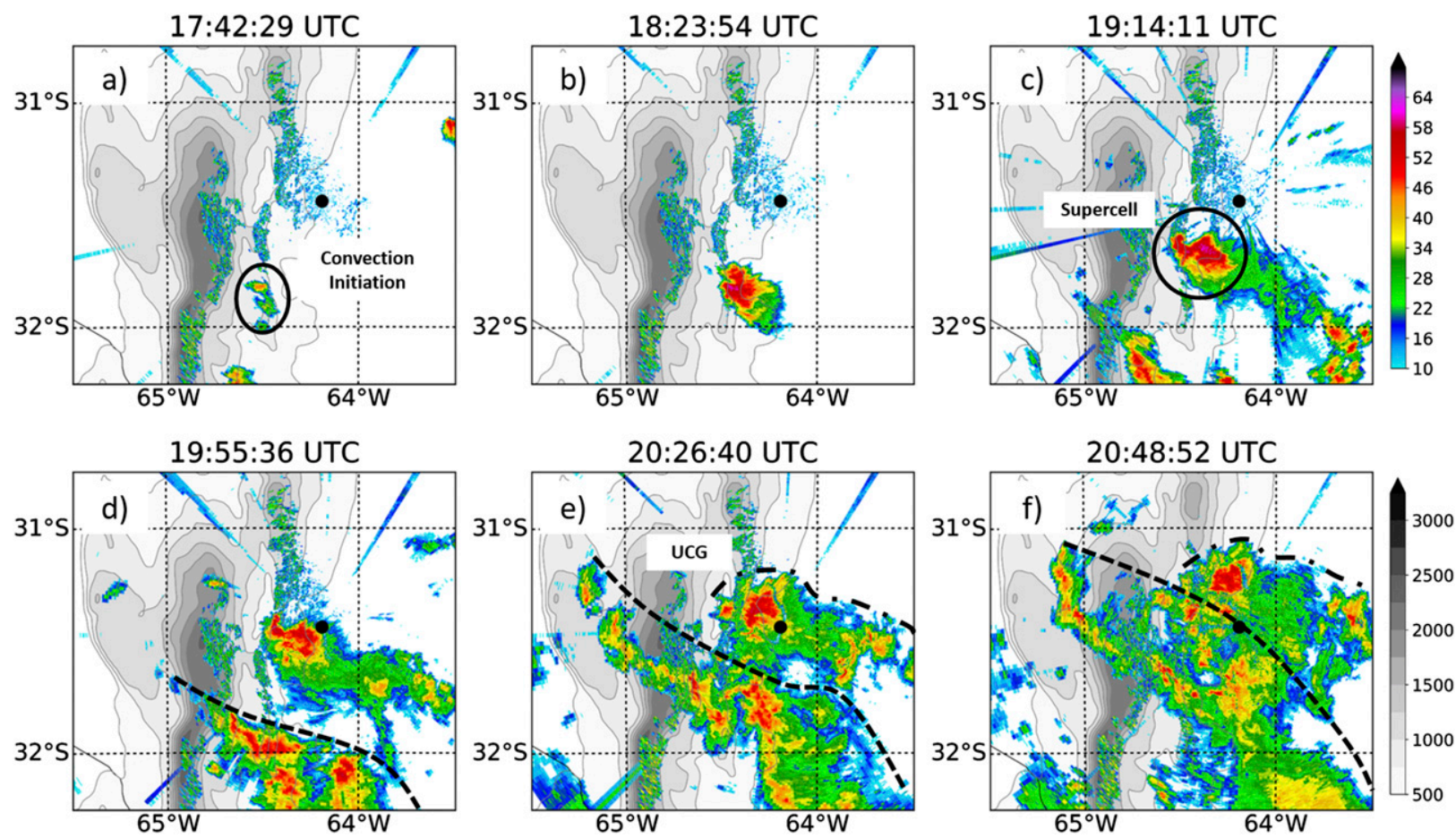

FIG. 6. $\sim 1^{\circ}$ Córdoba C-band radar reflectivity (color shaded; dBZ), terrain height (shaded and contoured in gray every $500 \mathrm{~m}$ ), and Córdoba (black dot) valid at: (a) 1742:29 UTC, (b) 1823:54 UTC, (c) 1914:11 UTC, (d) 1955:36 UTC, (e) 2026:40 UTC, and (f) 2048: 52 UTC. Convection initiation, peak supercell, and initial upscale convective growth stages are annotated in (a), (c), and (e), respectively. The approximate outflow boundary location from the northern supercell is denoted by a dot-dashed black line and the approximate outflow boundary location from the southern frontal MCS is denoted by a dashed black line.

experiment between these times ( $\sim 1540$ UTC). One explanation for the earlier CI time in the higher terrain experiments is that the increased terrain height of the SDC acted as an enhanced elevated heat source (relative to the cooler surrounding ambient air), which resulted in lower hydrostatic pressure. This led to an enhanced horizontal pressure gradient force directed toward the higher terrain (not shown; see Geerts et al. 2008), with an increase in low-level upslope flow. The elevated heating is best highlighted by the "bent back" isentropes over the SDC terrain peak, with ridgetop potential temperatures $\sim 310 \mathrm{~K}$ surrounded by potential temperatures at the same altitude of $\sim 308 \mathrm{~K}$ in the HIGH-40 experiment (e.g., Fig. 2j). Furthermore, a standing mountain wave was evident in higher terrain experiments (Figs. 2i,j). This mountain wave, with an upward branch located near the CI location (slightly east of the SDC) in the higher terrain experiments, had upward vertical velocities $\sim 1-4 \mathrm{~m} \mathrm{~s}^{-1}$. The higher terrain experiments also displayed lower mixed-layer level of free convection (MLLFC) heights over the ridgetops of the SDC, which, when combined with the enhanced vertical motions from the standing mountain wave and convergent upslope low-level flow, help explain the earlier $\mathrm{CI}$ in the diurnal cycle for these experiments
(Fig. 10, bottom row). In the lower terrain experiments, this mountain wave was nonexistent (Figs. 2f,g) and MLLFC heights were generally higher over the terrain (Figs. 10f,g). In terms of CI location, the higher terrain experiments had CI which occurred farther north, closer to low-level convergent flow located over the highest elevations of the SDC (Figs. 9d,e; near $31.75^{\circ} \mathrm{S}, 64.75^{\circ} \mathrm{W}$ ).

Peak supercell stages occurred at different times and different locations for the five terrain experiments (Fig. 9, bottom row). All supercells had similar peak upward vertical velocities $\left(34-37 \mathrm{~m} \mathrm{~s}^{-1}\right)$; however, the higher terrain supercells had slightly stronger peak downdrafts $\left(-17.7 \mathrm{~m} \mathrm{~s}^{-1}\right.$ in LOW-40 experiment and $-23.2 \mathrm{~m} \mathrm{~s}^{-1}$ in HIGH-40 experiment; not shown). The time from CI until peak supercell stage for each terrain experiment was generally similar and was $\sim 3-4 \mathrm{~h}$ (Table 2). The time from peak supercell stage until the beginning stages of UCG, however, was quite different and was fastest for the CTRL-0 (40 min) and HIGH-25 $(1 \mathrm{~h} 10 \mathrm{~min})$ experiments as compared with the other terrain experiments (Table 2; Fig. 11, bottom row). In fact, the LOW-40 and LOW-25 terrain supercells never underwent UCG as per the quantitative definition outlined in section $2 \mathrm{~d}$. Instead, the frontal MCS in these experiments was stronger, faster and overtook 

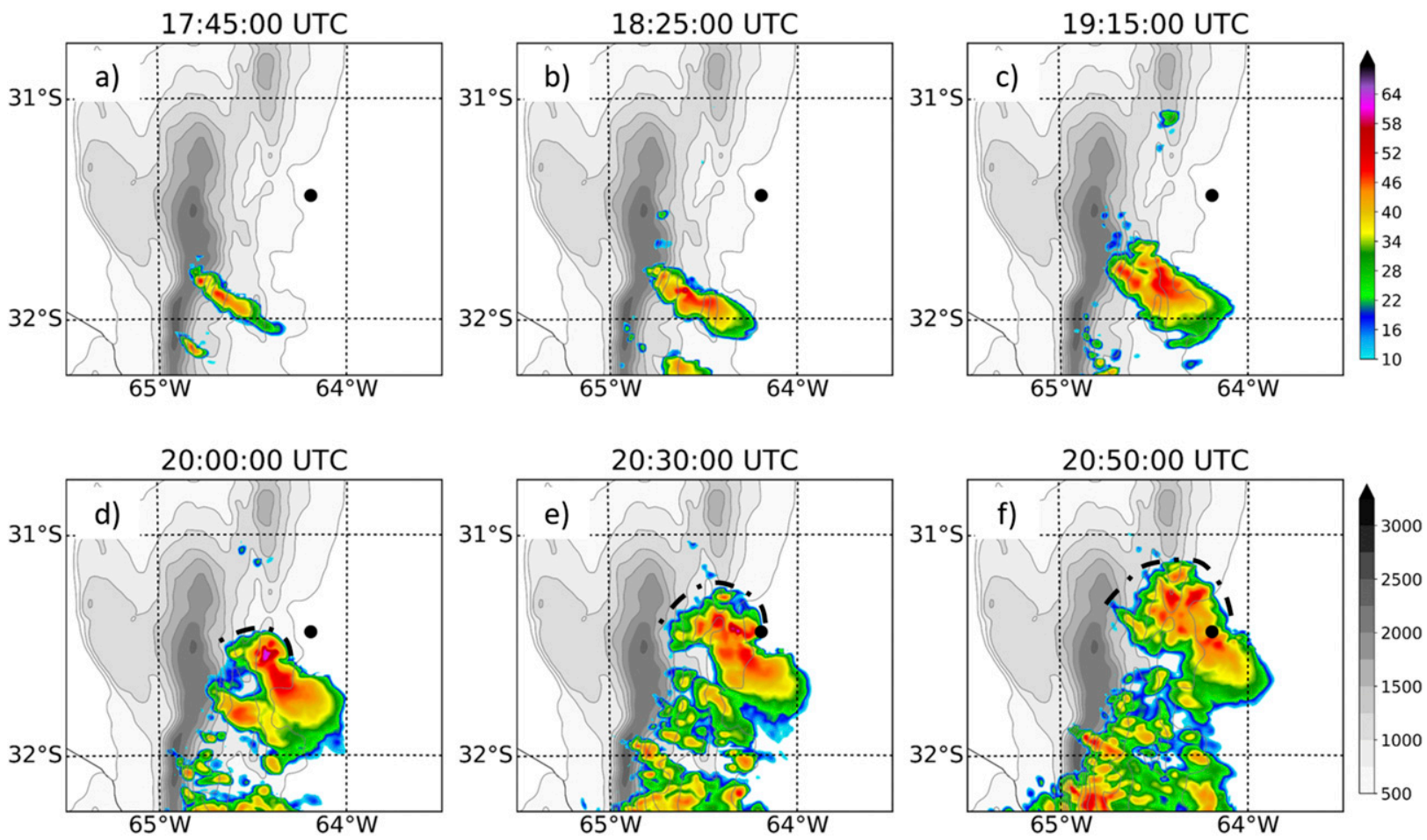

FIG. 7. As in Fig. 6, but displaying lowest model level reflectivity (color shaded; dBZ) from 1 km CTRL-0 WRF output. All annotations have been omitted along with the frontal MCS's outflow boundary position.

the initial isolated (and slightly weaker) supercell (Figs. 11a,b,f,g).

The indirect effects on storm morphology by changing the SDC terrain height were associated with environmental alterations near and surrounding the SDC. During CI stage, higher terrain experiments displayed lower magnitudes of MLCAPE (Fig. 12, top row). Time series of inflow-averaged (across $40 \mathrm{~km} \times$ $40 \mathrm{~km}$ purple box in Fig. 12, top row) MLCAPE leading up to CI stage varied from $\sim 1000-1200 \mathrm{~J} \mathrm{~kg}^{-1}$ in the LOW-40 experiment to $\sim 600-800 \mathrm{~J} \mathrm{~kg}^{-1}$ in the HIGH-40 experiment (Fig. 13a). Average soundings across the same box at CI time revealed that higher terrain experiments displayed an environment with lower low-level mixing ratios, greater mixed-layer depths, and higher mixed-layer lifting condensation levels (MLLCL) and MLLFCs, resulting in the lower magnitudes of MLCAPE (Fig. 14; Figs. 13c,d;). The higher MLLCLs within the inflow region of the higher terrain supercells likely explain the slightly stronger downdrafts as compared to the lower terrain supercells owing to greater subcloud evaporative cooling. Furthermore, regions where the terrain was raised, low-level moisture inherently was reduced owing to the lower atmosphere being removed (not shown). MLCIN was minimal over the north-south extent of the SDC crest, with increasing magnitudes of MLCIN to the east over lower elevations (Fig. 12, top row).

During peak supercell stage, MLCAPE was generally similar across all experiments within the inflow regions of the supercells (Fig. 12; bottom row). MLCIN, however, was generally greater within the inflow region of LOW-40 and LOW-25 supercells with negligible MLCIN within the inflow regions of CTRL-0, HIGH-25, and HIGH-40 supercells (Fig. 12; bottom row). MLCIN increased toward lower elevations in all terrain height experiments, where greater turbulent vertical mixing and thus, lower magnitudes of low-level moisture, existed (e.g., Figs. $3 \mathrm{~b}$ and 12, bottom row). These trends in MLCAPE/MLCIN further continued throughout the UCG stage (Fig. 15).

The terrain alterations also resulted in changes to the low-level and deep-layer vertical wind shear profiles. All terrain experiments displayed a narrow north-southoriented ribbon of enhanced low-level vertical wind shear along the eastern slopes of the SDC (Fig. 16). These results qualitatively resemble those in idealized modeling studies conducted by Markowski and Dotzek (2011) and Soderholm et al. (2014), real data modeling studies by Miglietta et al. (2017) and Scheffknecht et al. (2017), and observations by Bosart et al. (2006). This enhanced low-level vertical wind shear east of the terrain likely owed to diurnally driven upslope flows, as 


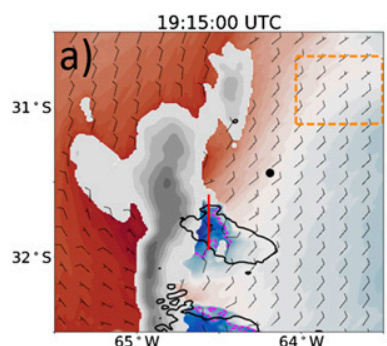

19:15:00 UTC

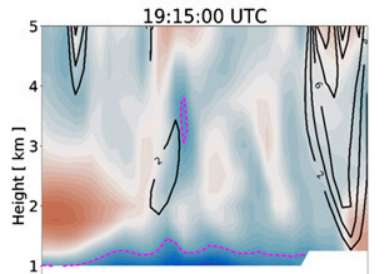

e)

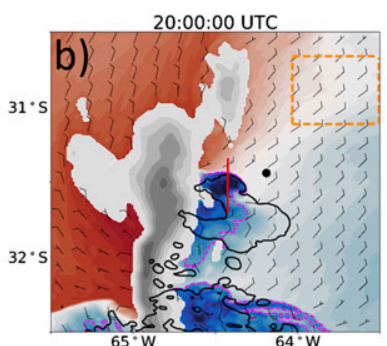

20:00:00 UTC

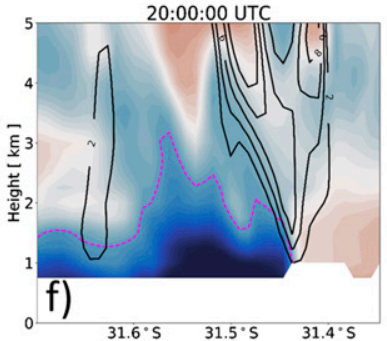

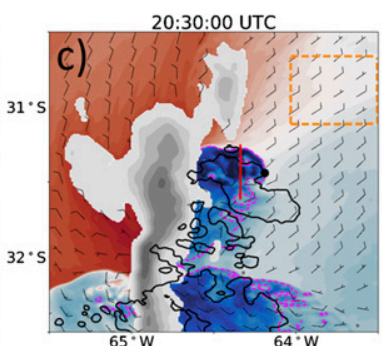

20:30:00 UTC

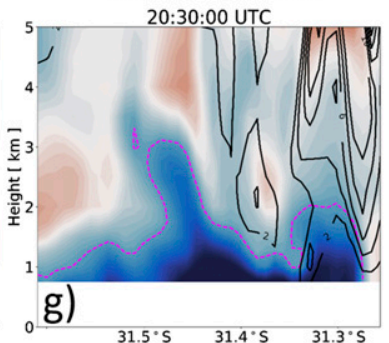

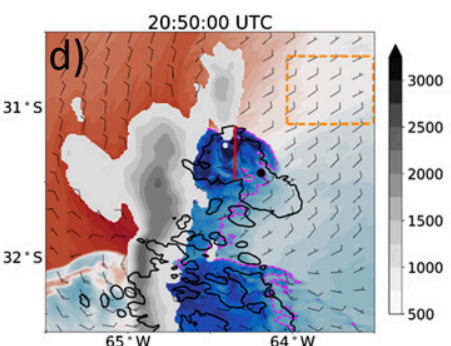

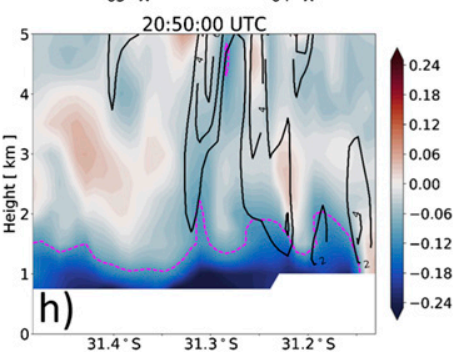

FIG. 8. $1 \mathrm{~km}$ CTRL-0 WRF output depicting: (a)-(d) $\sim 1 \mathrm{~km}$ thermal buoyancy (color shaded; $\mathrm{m} \mathrm{s}^{-2}$ ), $-0.1 \mathrm{~m} \mathrm{~s}^{-2}$ thermal buoyancy contour (magenta lines), $30 \mathrm{dBZ}$ lowest model level reflectivity contour (black lines), $\sim 1 \mathrm{~km}$ horizontal winds (half barb $=5 \mathrm{~m} \mathrm{~s}^{-1}$, full barb $=10 \mathrm{~m} \mathrm{~s}^{-1}$ ), terrain height (shaded in gray every $250 \mathrm{~m}$ starting at $500 \mathrm{~m}$ ), Córdoba (black dot), the location of the north-to-south oriented vertical cross sections (red lines) shown in the bottom row, and the box which represented the average inflow conditions used to calculate thermal buoyancy (orange dashed lines; see text for details). (e)-(h) Vertical cross sections taken along red lines in (a)-(d) depicting thermal buoyancy (shaded; $\mathrm{m} \mathrm{s}^{-2}$ ), $-0.1 \mathrm{~m} \mathrm{~s}^{-2}$ thermal buoyancy contour (magenta lines), and positive vertical velocity (contoured in black every $2 \mathrm{~m} \mathrm{~s}^{-1}$ starting at $2 \mathrm{~m} \mathrm{~s}^{-1}$ ). The corresponding WRF output times are listed in the title above each panel.

evidenced by the northeasterly low-level winds (e.g., composite wind hodograph in Fig. 14b). Magnitudes of $0-2 \mathrm{~km}$ AGL BWD averaged within the CI inflow region revealed that higher terrain experiments displayed $\sim 3-4 \mathrm{~m} \mathrm{~s}^{-1}$ greater low-level vertical wind shear as compared to lower terrain experiments through first few hours of the simulation (Fig. 13e;). This low-level vertical wind shear and corresponding negative stormrelative helicity (antistreamwise horizontal vorticity; not shown) supported supercell formation in all experiments;
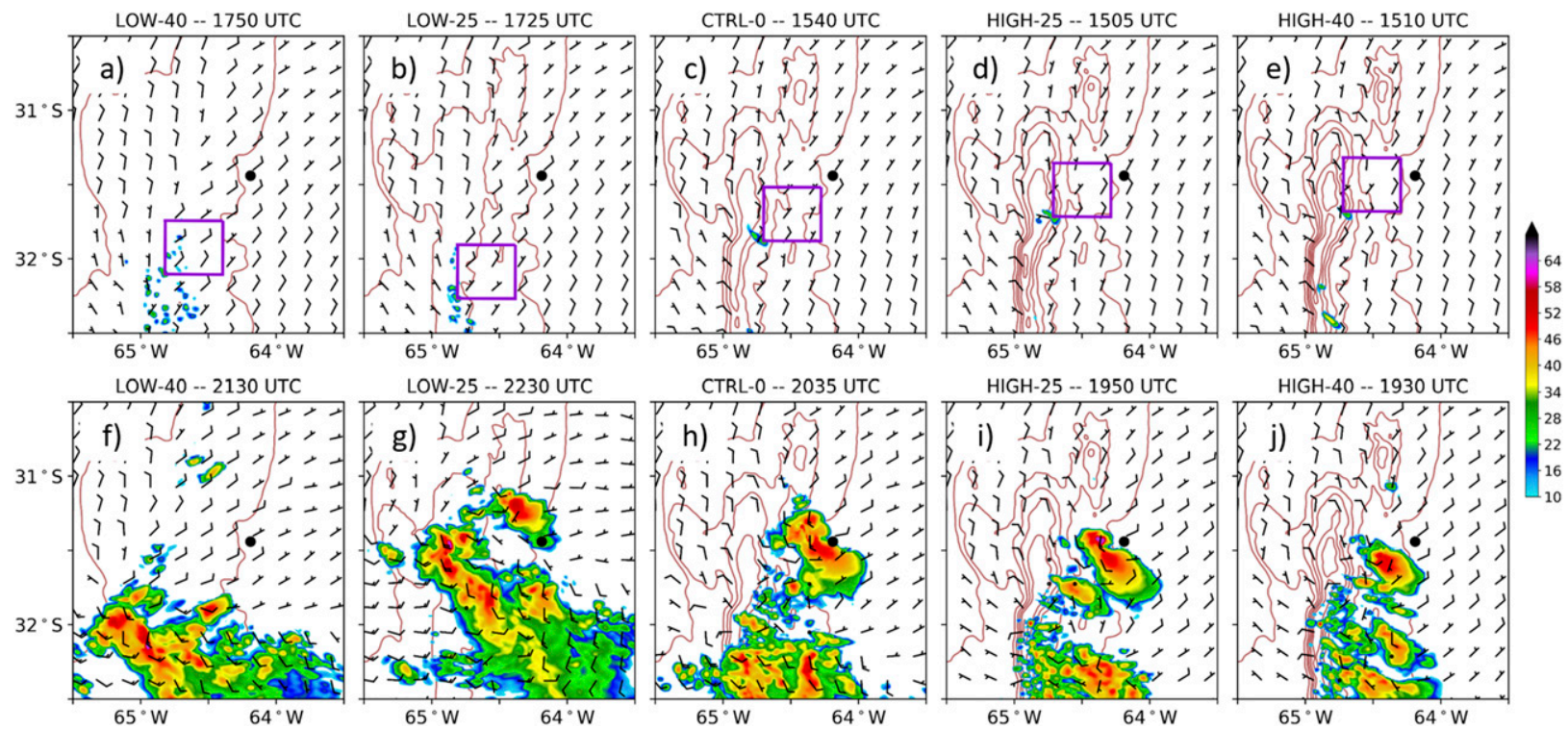

FIG. $9.1 \mathrm{~km}$ WRF output depicting: lowest model level reflectivity (shaded; dBZ), horizontal winds averaged over the lowest 10 sigma levels (half barb $=5 \mathrm{~m} \mathrm{~s}^{-1}$, full barb $=10 \mathrm{~m} \mathrm{~s}^{-1}$ ), terrain height (contoured in brown every $500 \mathrm{~m}$ starting at $500 \mathrm{~m}$ ), and Córdoba (black dot). The purple boxes in the top row are located with the southwest corner centered at convection initiation locations and are used to calculate average atmospheric quantities displayed in Figs. 13 and 14 (see text for additional details). The corresponding WRF output times and terrain experiments are listed in the title above each panel. 
TABLE 2. Summary of the different stages of convective morphology by terrain experiment.

\begin{tabular}{|c|c|c|c|c|c|}
\hline & LOW-40 & LOW-25 & CTRL-0 & HIGH-25 & HIGH-40 \\
\hline Convection initiation & $1750 \mathrm{UTC}$ & 1725 UTC & 1540 UTC & 1505 UTC & 1510 UTC \\
\hline Peak supercell & 2130 UTC & 2230 UTC & 2035 UTC & 1950 UTC & 1930 UTC \\
\hline Initial upscale convective growth & None & None & 2115 UTC & 2100 UTC & $2125 \mathrm{UTC}$ \\
\hline$\Delta t($ Supercell $\rightarrow \mathrm{UCG})$ & $\mathrm{N} / \mathrm{A}$ & N/A & $0 \mathrm{~h} 40 \mathrm{~min}$ & $1 \mathrm{~h} 10 \mathrm{~min}$ & $1 \mathrm{~h} 55 \mathrm{~min}$ \\
\hline
\end{tabular}

however, once the simulated storms moved eastward off the terrain, the low-level inflow environments became increasingly less favorable for supercell sustenance (i.e., weaker low-level vertical wind shear, higher inflow MUCIN).

Similar to the low-level vertical wind shear trends, an analysis of $0-8 \mathrm{~km}$ AGL BWD revealed $\sim 3-4 \mathrm{~m} \mathrm{~s}^{-1}$ greater vertical wind shear in higher terrain experiments as compared to lower terrain experiments through the first few hours of the simulation (Figs. 13f and 14b). The greater deep-layer vertical wind shear in higher terrain experiments was a likely by-product of the earlier CI time and farther north CI location which was closer in proximity to the upper-level jet streak over the region (e.g., Fig. 3a). The delayed CI time and southern SDC CI location for lower terrain experiments allowed for the upper-level trough and corresponding jet streak to move farther eastward, with a tendency for slowly weakening upper-level winds over time. This is highlighted in the inflow-averaged sounding and hodograph that depicted weaker southwesterly upper-level winds $\left(\sim 20-25 \mathrm{~m} \mathrm{~s}^{-1}\right)$ in lower terrain experiments and stronger northwesterly winds $\left(25-30 \mathrm{~m} \mathrm{~s}^{-1}\right)$ in higher terrain experiments at convection initiation (Fig. 14). Throughout UCG, stronger deep-layer vertical wind shear was found in higher terrain experiments with comparable (within 1-2 $\mathrm{m} \mathrm{s}^{-1}$ ) low-level vertical wind shear across all terrain experiments (Fig. 17). Perhaps noteworthy, the southwesterly deep-layer vertical wind shear vectors were nearly parallel to the north-south orientation of the SDC in the CTRL-0 experiment, which, correspondingly, had the faster UCG rate (e.g., Fig. 16h; Table 2). This echoes the results of Dial et al. (2010) who showed that when deep-layer vertical wind shear vectors were more parallel to a low-level forcing boundary (in this case, the terrain), that the rate of UCG increased. In higher terrain experiments, deep-layer vertical wind shear vectors were stronger and predominately west-northwesterly, crossing the high terrain at a more
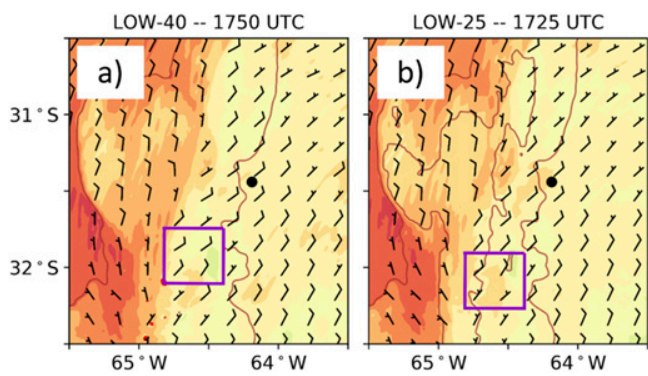

LOW-40 - 1750 UTC
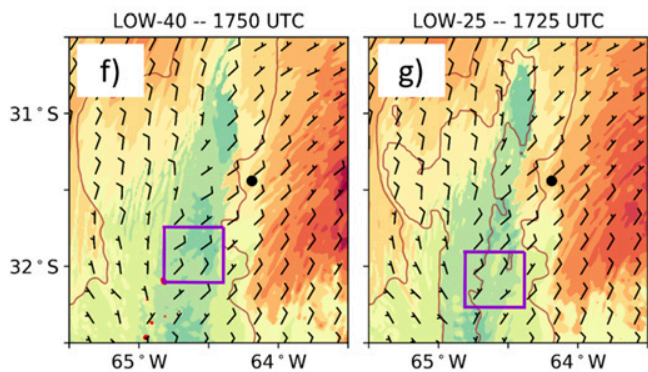
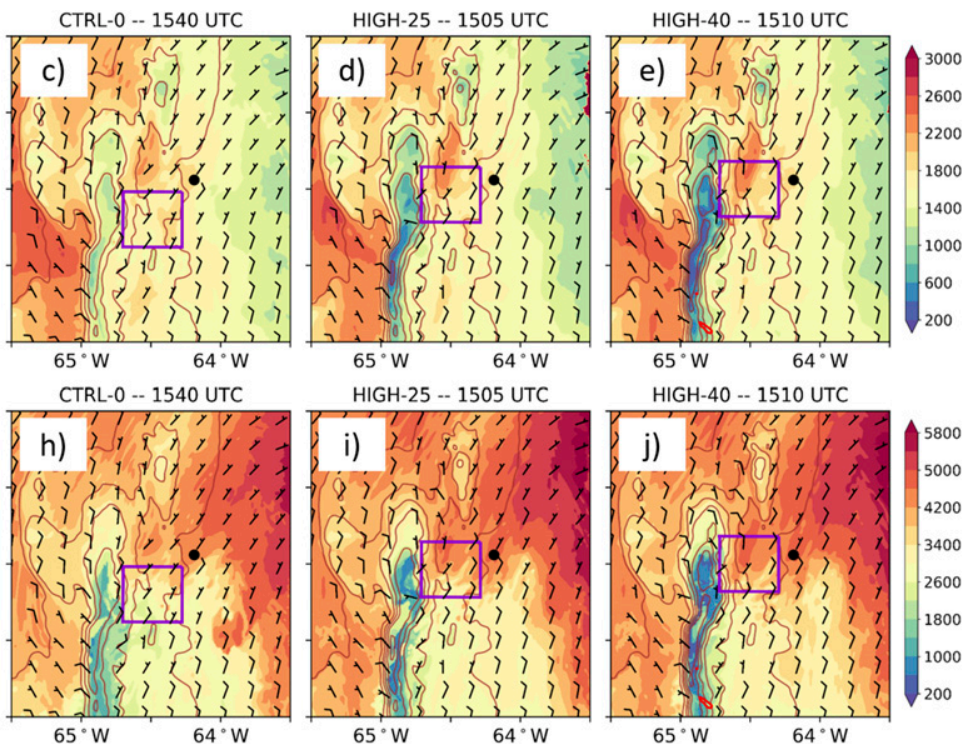

HIGH-40 -- 1510 UTC

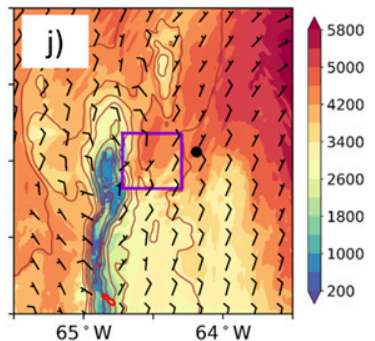

FIG. 10. $1 \mathrm{~km}$ WRF output at convection initiation time depicting: (a)-(e) mixed-layer LCL height (shaded, m), $30 \mathrm{~dB} Z$ lowest model level reflectivity contour (red lines), horizontal winds averaged over the lowest 10 sigma levels (half barb $=5 \mathrm{~m} \mathrm{~s}^{-1}, \mathrm{full} \mathrm{barb}=10 \mathrm{~m} \mathrm{~s}{ }^{-1}$ ), terrain height (contoured in brown every $500 \mathrm{~m}$ starting at $500 \mathrm{~m}$ ), and Córdoba (black dot). (f)-(j) As in (a)-(e), but displaying mixedlayer LFC height (color shaded; $\mathrm{m}$ ). The purple boxes are located with the southwest corner centered at convection initiation locations and are used to calculate average atmospheric quantities displayed in Figs. 13 and 14 (see text for additional details). The corresponding WRF output times and terrain experiments are listed in the title above each panel. 

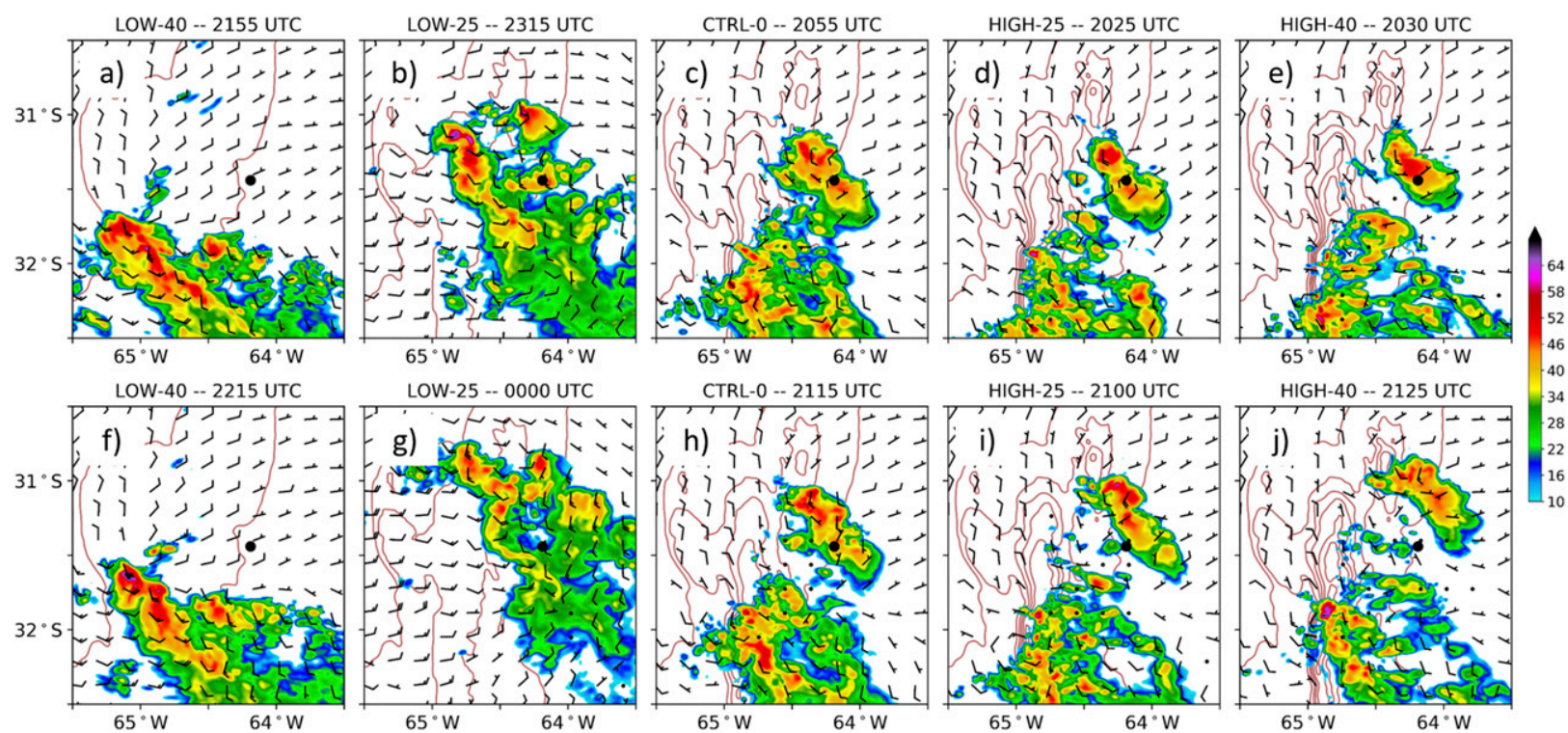

$65^{\circ} \mathrm{W}$

$64^{\circ} \mathrm{W}$

FIG. 11. As in Fig. 9, but for later WRF output times. The corresponding WRF output times and terrain experiments are listed in the title above each panel.

oblique angle which supported a lengthier period of supercell sustenance (Figs. 16d,e,i,j).

To summarize thus far, MLCAPE generally decreased and low-level/deep-layer vertical wind shear generally increased for higher terrain experiments (and vice versa for lower terrain experiments). This was mainly true within the nearest $25-50 \mathrm{~km}$ east of the altered terrain peak. The larger magnitudes of low-level and deep-layer vertical wind shear in the higher terrain experiments resulted in a more intense supercell that took longer to grow upscale into an MCS relative to the CTRL-0 experiment. In the lower terrain experiments, the frontal MCS was stronger and faster owing to greater MLCAPE, resulting in a leading orographic supercell that was simply overrun by the frontal MCS and thus, did not undergo UCG as defined in this study.

To further explain the difference in UCG rates between the terrain experiments, cold pool analyses during
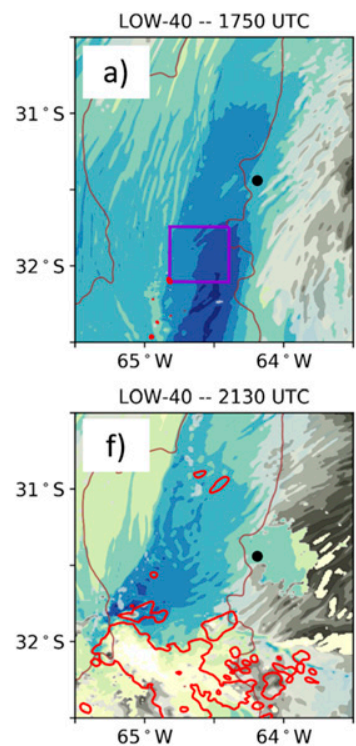

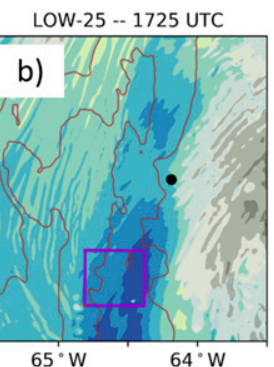

LOW-25 -- 2230 UTC

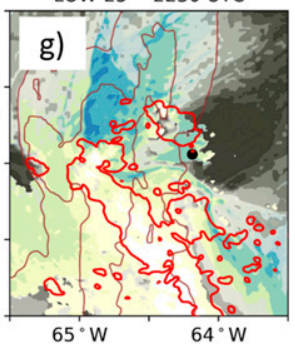

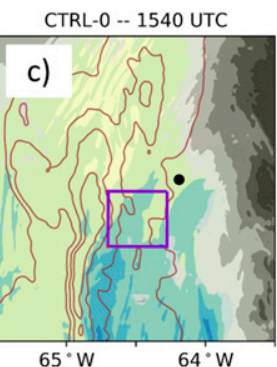

CTRL-0 -- 2035 UTC

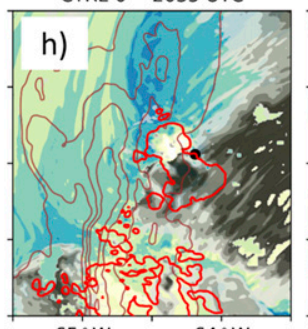

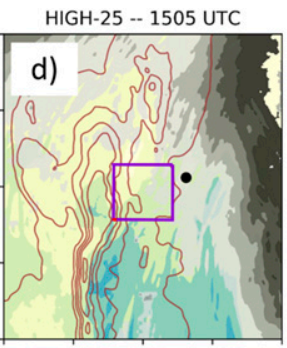

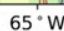

HIGH-25 - 1950 UTC

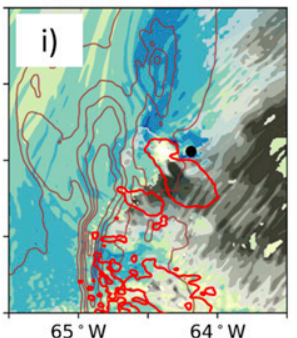

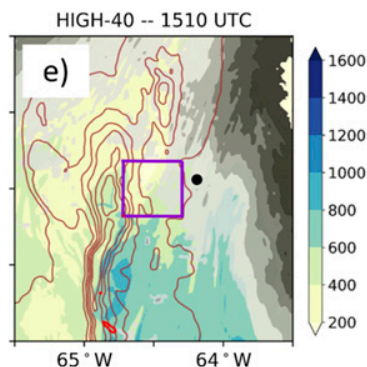

HIGH-40 -- 1930 UTC

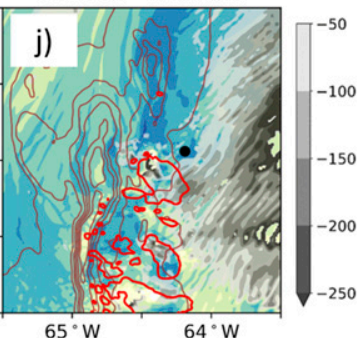

FIG. 12. As in Fig. 9, but displaying mixed-layer CAPE (color shaded; $\mathrm{J} \mathrm{kg}^{-1}$ ), mixed-layer CIN (gray shaded; $\mathrm{J} \mathrm{kg}^{-1}$ ), and $30 \mathrm{dBZ}$ lowest model level reflectivity (red lines). The corresponding WRF output times and terrain experiments are listed in the title above each panel. 

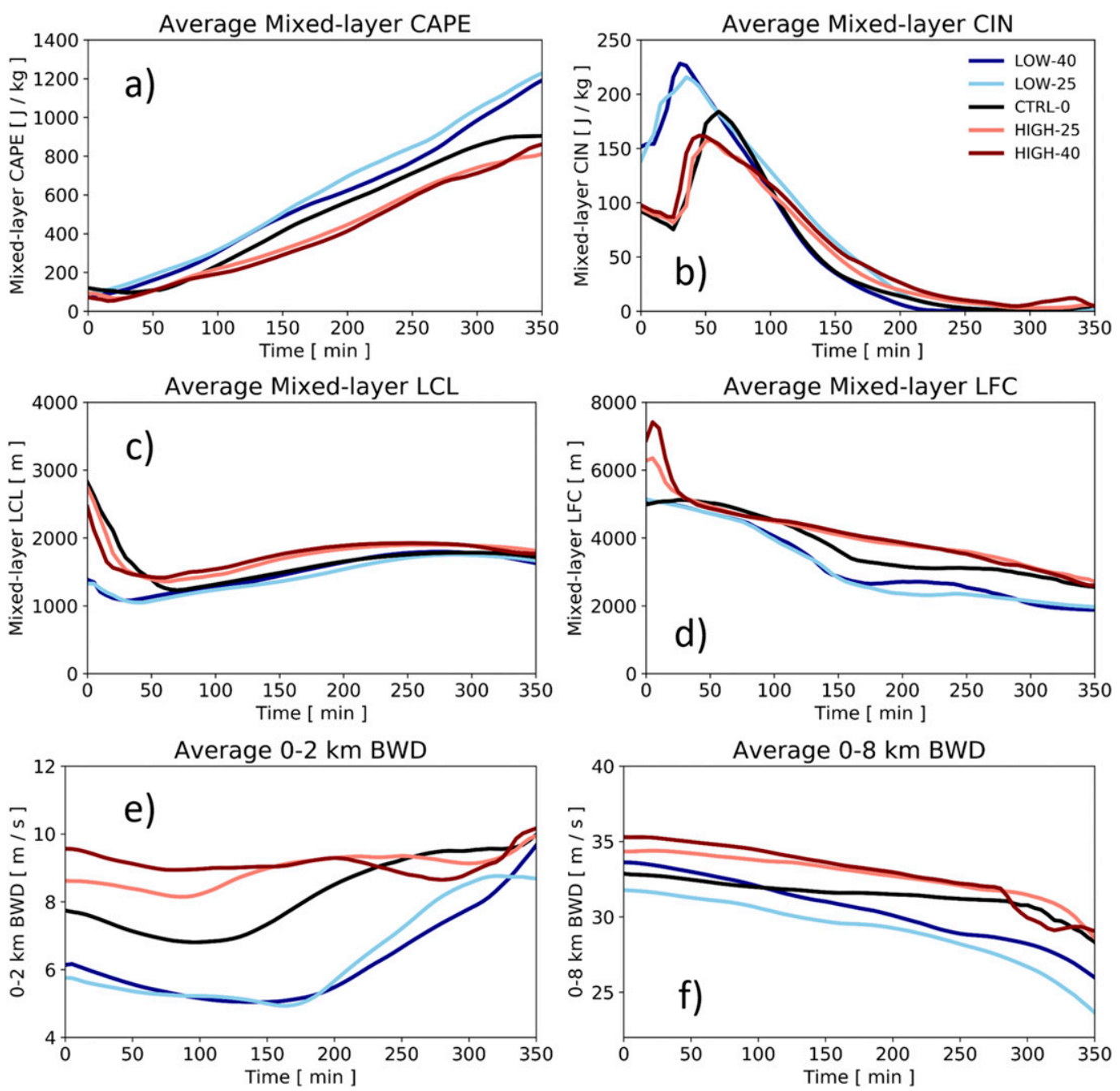

FIG. 13. Time series of various atmospheric quantities averaged over region depicted by purple boxes in Fig. 9 (top row). (a) Mixed-layer CAPE $\left(\mathrm{J} \mathrm{kg}^{-1}\right)$, (b) mixed-layer CIN $\left(\mathrm{J} \mathrm{kg}^{-1}\right)$, (c) mixed-layer LCL height (m), (d) mixed-layer LFC height (m), (e) 0-2 km AGL BWD $\left(\mathrm{m} \mathrm{s}^{-1}\right)$, and (f) 0-8 km AGL BWD (m s${ }^{-1}$ ).

peak supercell stage were conducted, except on the LOW-40 supercell since it was the most directly impacted by the frontal MCS and did not undergo UCG as outlined in this research. The low-level cold pool was the strongest in the CTRL-0 and HIGH-25 supercells and weakest in the LOW-25 and HIGH-40 supercells (Fig. 18; Table 3). North-south vertical cross sections through the coldest portion of the cold pools also revealed that the CTRL-0 and HIGH-25 experiments had the deepest cold pools compared with the other terrain experiments, with peak cold pool depths of $\sim 2.75 \mathrm{~km}$ and $\sim 1.75 \mathrm{~km}$, respectively (Fig. 18, bottom row; Table 3). In higher terrain experiments, low-level cold pools were blocked by the higher terrain of the SDC to the west, likely leading to the increased cold pool depth, especially within the CTRL-0 and
HIGH-25 supercells. In the LOW-25 experiment, the low-level cold pool spread laterally outward at a more efficient rate with little terrain blocking of the negatively buoyant air (Fig. 18a). Droegemeier and Wilhelmson (1987) showed that depth was the most important cold pool property (as compared to strength or speed) related to deep/intense gust front lifting and a corresponding higher potential for secondary CI. Furthermore, the mean lower-tropospheric winds became more perpendicular (nearly opposite) to that of the cold pool (and storm) motion with increasing terrain height, which has been shown to support robust low-level lifting (Fig. 18, top row; e.g., Wilson et al. 1998). As a result, in the CTRL-0 and HIGH-25 experiments, lower-tropospheric upward vertical velocities of $1-5 \mathrm{~m} \mathrm{~s}^{-1}$ were located along the outflow 


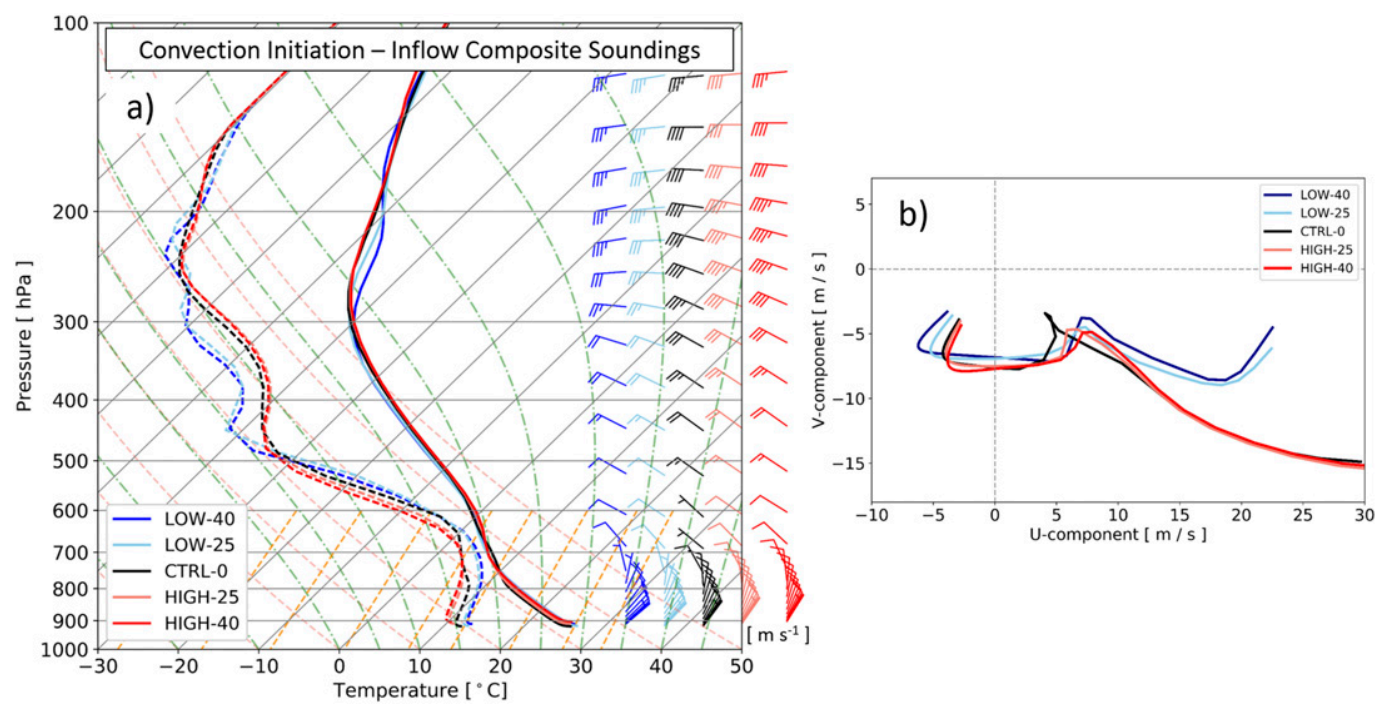

FIG. 14. (a) Composite soundings (averaged over region depicted by purple boxes in Fig. 9, top row) plotted on a skew $T-\log p$ diagram at convection initiation. The rightmost solid lines are temperature $\left({ }^{\circ} \mathrm{C}\right)$ and the leftmost dashed lines are dewpoint temperature $\left({ }^{\circ} \mathrm{C}\right.$ ). Horizontal winds are plotted on the right (half barb $=5 \mathrm{~m} \mathrm{~s}^{-1}$, full barb $\left.=10 \mathrm{~m} \mathrm{~s}^{-1}\right)$. (b) Composite wind hodograph traces $\left(\mathrm{m} \mathrm{s}^{-1}\right)$ corresponding to the composite soundings in (a) between the lowest model level and $\sim 10 \mathrm{~km}$ AGL.

boundary, which were much greater than in the other terrain experiments (Fig. 18, bottom row).

The initially deeper and stronger cold pools, and corresponding stronger gust front upward vertical velocities in the CTRL-0 and HIGH-25 supercells likely help explain, at least in part, the tendency for the quickest transition of this orographic supercell into an MCS relative to the other terrain experiments. Strong negative buoyancy was found within the rear-flank downdraft regions of the simulated supercells in these experiments. The subsequent deep and surging outflow, along with minimal inflow MLCIN, aided in secondary CI along the gust front boundary, fostering more rapid UCG. Reduced terrain blocking of the LOW-25 supercell's cold pool reduced the rate of increase in cold pool depth, likely explaining why this

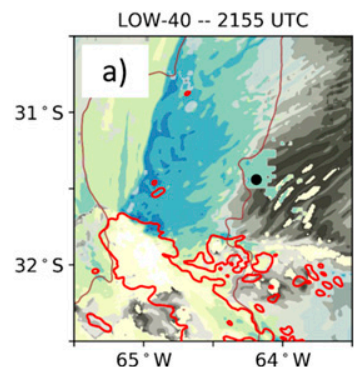

LOW-40 -- 2215 UTC
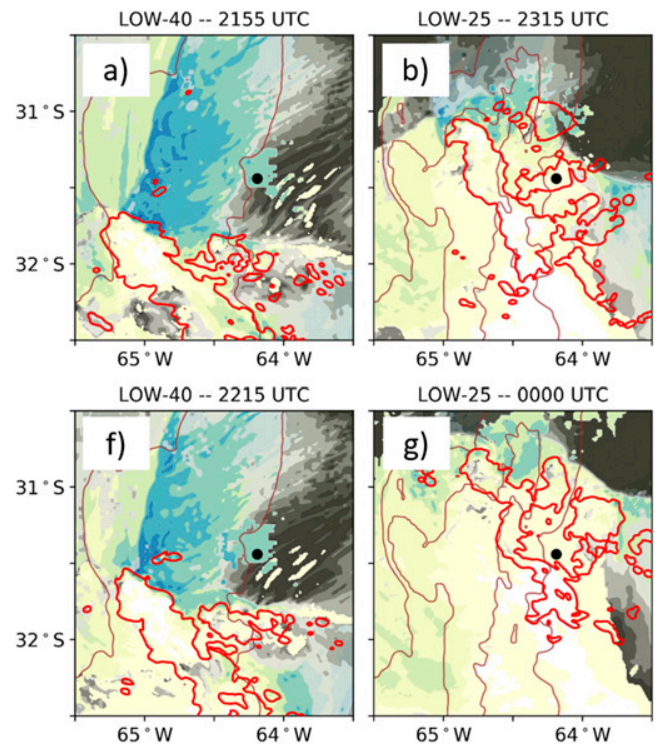

LOW-25 -- 0000 UTC

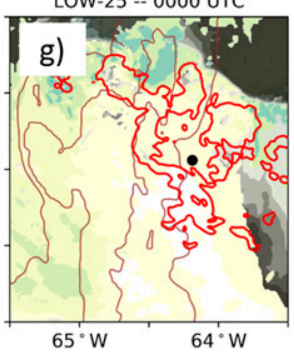

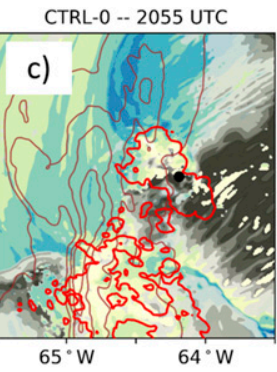

CTRL-0 -- 2115 UTC

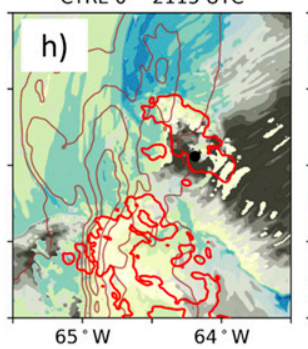

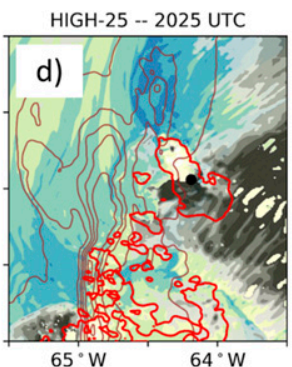

HIGH-25 -- 2100 UTC

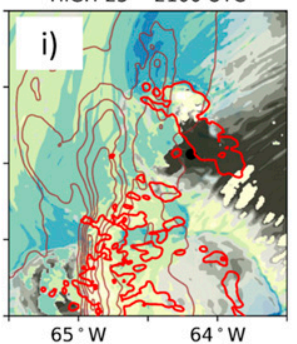

HIGH-40 -- 2030 UTC

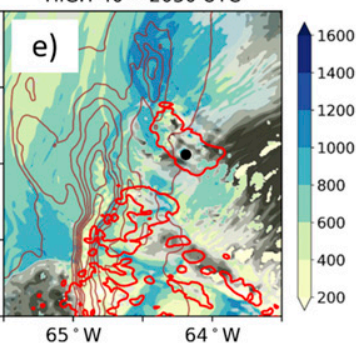

HIGH-40 -- 2125 UTC

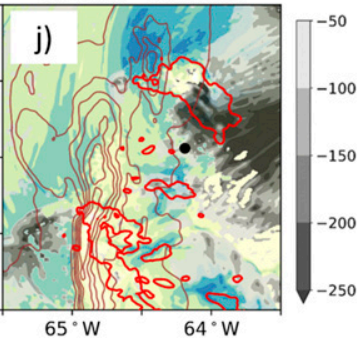

FIG. 15. As in Fig. 12, but for later WRF output times. The corresponding WRF output times and terrain experiments are listed in the title above each panel. 

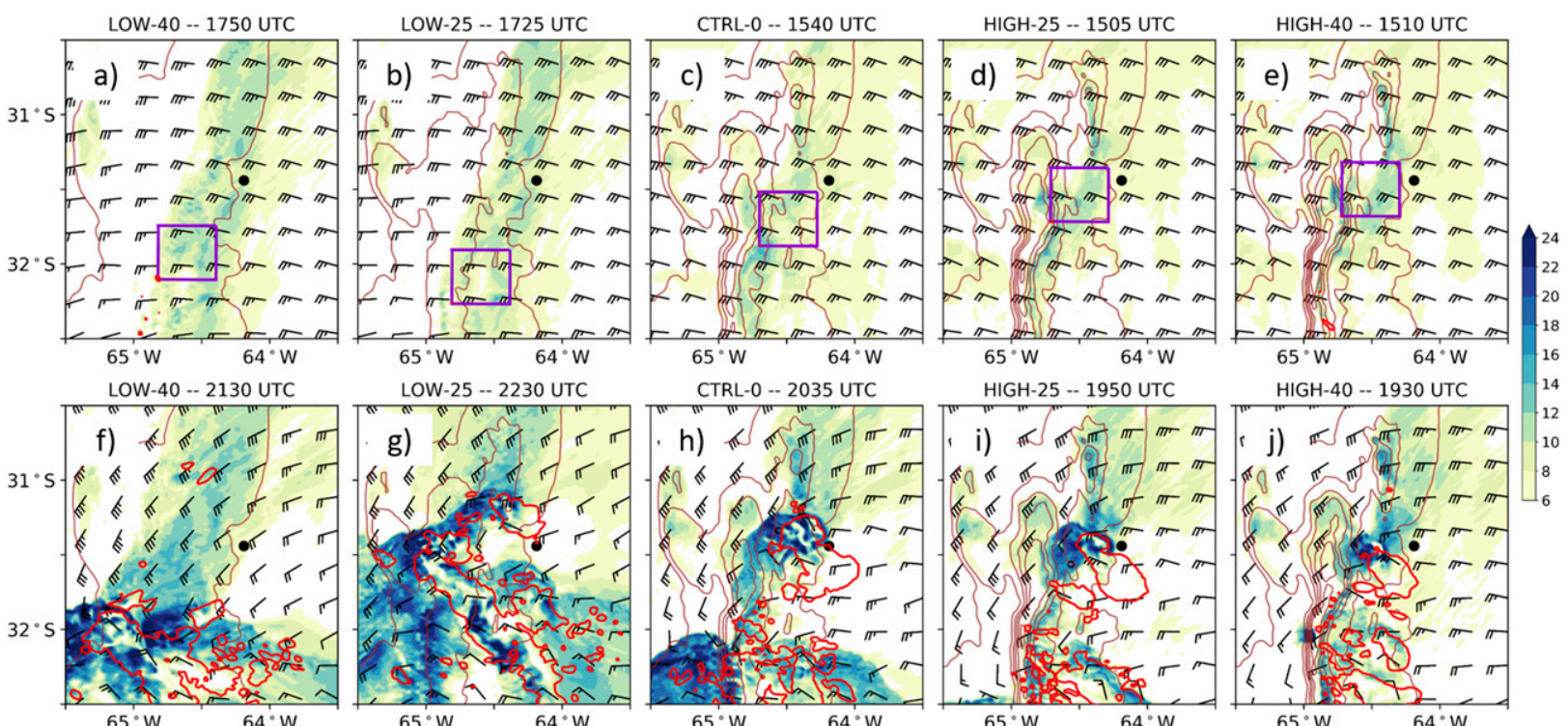

FIG. 16. As in Fig. 9, but displaying 0-2 AGL BWD (color shaded; $\mathrm{m} \mathrm{s}^{-1}$ ), 0-8 km AGL BWD (half barb $=5 \mathrm{~m} \mathrm{~s}^{-1}$, full barb $=10 \mathrm{~m} \mathrm{~s}{ }^{-1}$ ), and $30 \mathrm{dBZ}$ lowest model level reflectivity (red lines). The corresponding WRF output times and terrain experiments are listed in the title above each panel.

supercell did not grow upscale into an MCS as defined in this research.

\section{c. Trajectory analyses}

To further elucidate the thermodynamic cold pool properties of this supercell-to-MCS transition, parcel trajectories were computed within the cold pools of the simulated storms at peak supercell stage. Offline trajectories were computed via second-order semi-implicit discretization in space and time using 1 min output from the $1 \mathrm{~km}$ domains (Miltenberger et al. 2013; Gowan and Steenburgh 2018). The initial locations of the parcels were defined in a $12 \mathrm{~km} \times 12 \mathrm{~km} x-y$ grid (spaced evenly every $1 \mathrm{~km}$ on every model vertical level) centered at the coldest portion of the peak supercell's cold pool. From these starting locations, parcel trajectories were run backward in time $30 \mathrm{~min}$. Various thermodynamic quantities (e.g., RH, equivalent potential temperature)

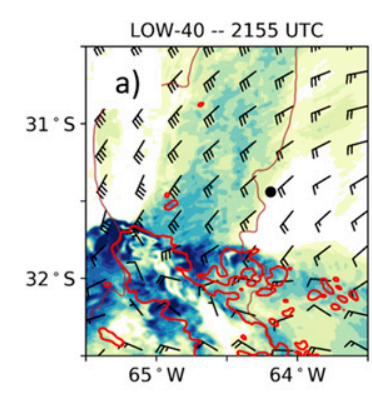

LOW-40 -- 2215 UTC

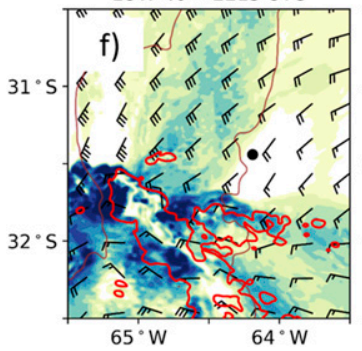

LOW-25 -- 2315 UTC

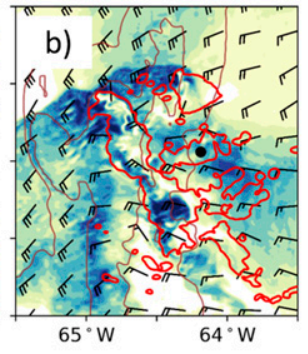

LOW-25 -- 0000 UTC

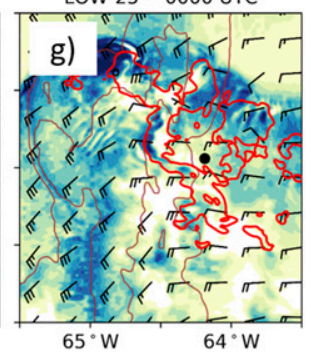

CTRL-0 -- 2055 UTC

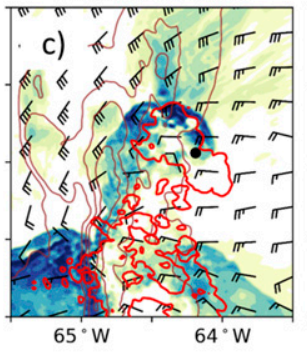

CTRL-0 -- 2115 UTC

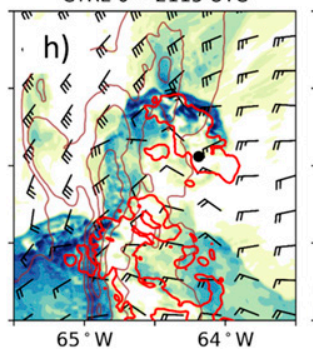

HIGH-25 -- 2025 UTC

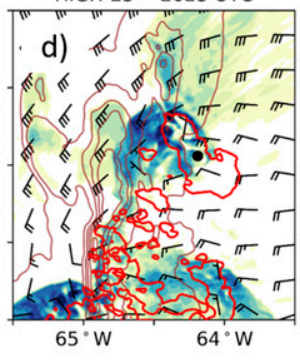

HIGH-25 - 2100 UTC

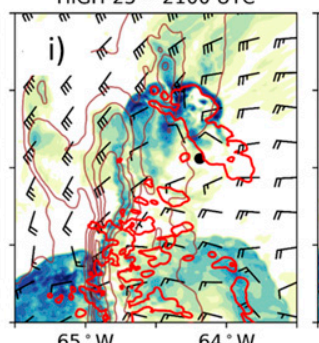

HIGH-40 -- 2030 UTC

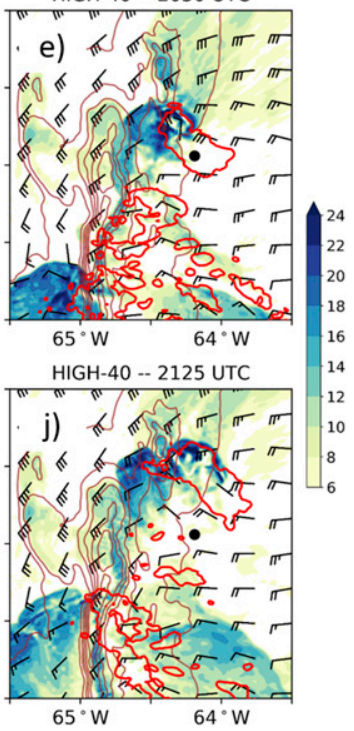

FIG. 17. As in Fig. 16, but for later WRF output times. The corresponding WRF output times and terrain experiments are listed in the title above each panel. 

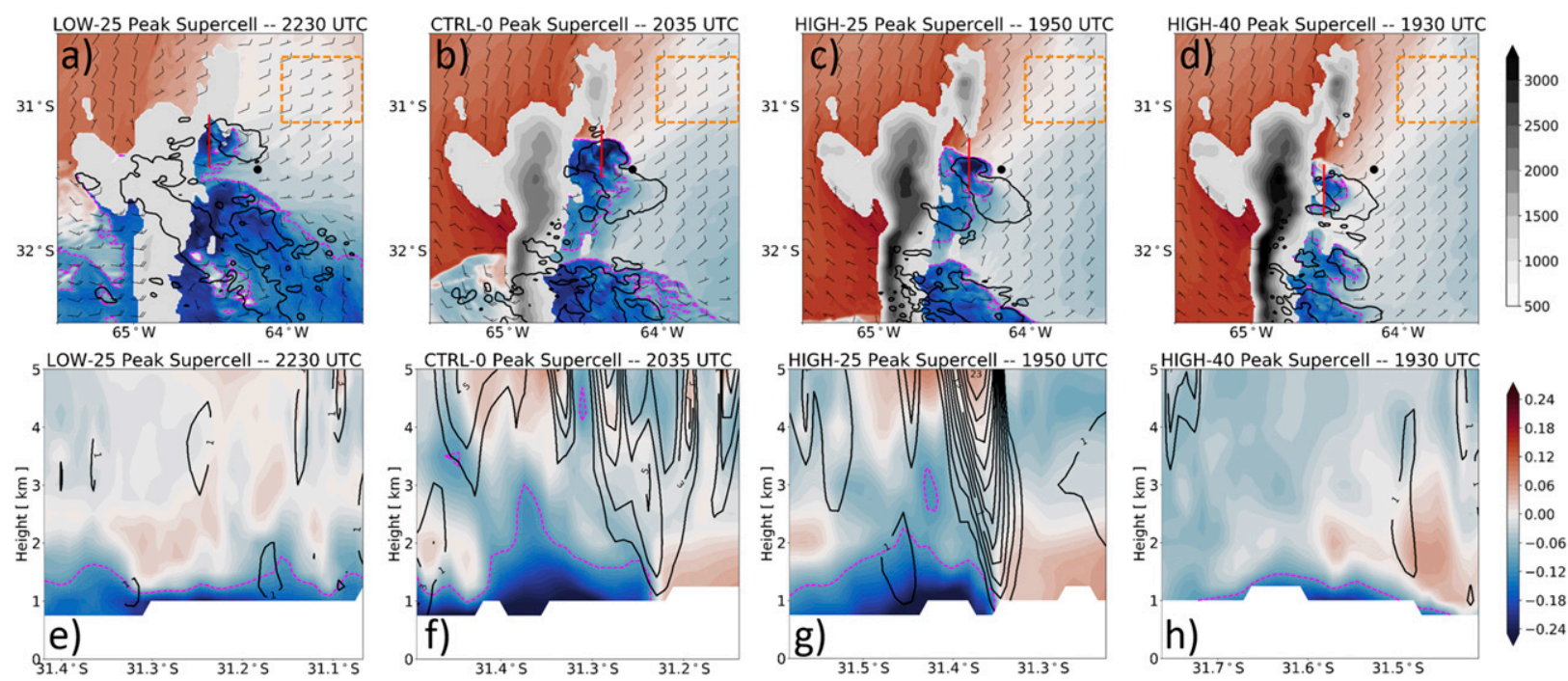

FIG. 18. As in Fig. 8, but for all terrain experiments (except for LOW-40) at peak supercell time. (bottom) As in Fig. 8, bottom row, but positive vertical velocity (contoured in black every $2 \mathrm{~m} \mathrm{~s}^{-1}$ starting at $1 \mathrm{~m} \mathrm{~s}^{-1}$ ). The corresponding WRF output times and terrain experiments are listed in the title above each panel.

were computed along the parcel trajectory paths to diagnose and understand cold pool properties and formation. Median, 25th, and 75th percentiles over the lowest 10 model levels of all parcel heights, equivalent potential temperatures $\left(\theta_{e}\right)$, and RHs were plotted and analyzed via time series (e.g., Fig. 19, bottom row).

A comparison of the horizontal paths for parcels ending at ground level (red lines) and just slightly above (orange lines) revealed that most of the air within the low-level cold pools came from the inflow (eastern) or southern sides (Fig. 19, top row). For the CTRL-0 and HIGH-25 experiments, however, some of the parcels that entered the low-level cold pool either originated over the higher terrain to the west or within the cold pool itself (Figs. 19b,c). The deepest cold pool was associated with the CTRL-0 simulated supercell (Table 3), which correspondingly had the greatest number of parcels originating over the higher terrain to the west (Fig. 19b). Parcels across all experiments experienced maximum downward vertical displacements between 3 and $4 \mathrm{~km}$ (black shading) with median decreases in $\theta_{e}$ between 3 and $5 \mathrm{~K}$ (red lines). Given that $\theta_{e}$ is conserved for adiabatic and pseudoadiabatic processes, the decrease in $\theta_{e}$ toward the low-level cold pool indicates that diabatic processes were responsible for its formation (e.g., evaporation, melting). This is supported by the increase in rain and graupel mass mixing ratios along the parcel paths with RH $<100 \%$. CTRL-0 and HIGH-25 parcels had the lowest initial median RH (60\%-80\%), which highlighted the potential for stronger evaporative cooling in these experiments, although not fully realized (Figs. 19f,g). The HIGH-40 parcels displayed the largest decreases in $\theta_{e}$ toward the low-level cold pool, likely due to a greater melting rate owing to the greater graupel mass mixing ratio (Fig. 19h). Overall, the trajectories revealed that decreases in $\theta_{e}$ along the parcel pathways owing to diabatic latent cooling were similar, suggesting that environmental (vertical wind shear, CAPE) and terrain (blocking of cold pools) factors were more instrumental to the eventual UCG of the orographic supercell than varying in-storm microphysical processes across the terrain experiments.

\section{Summary and conclusions}

This paper examined the role of terrain in the upscale convective growth process of an orographic supercell. High-resolution WRF simulations were conducted in which the terrain height of the SDC was systematically raised or lowered. The terrain height experiments

TABLE 3. Peak magnitude and depth of cold pool (based upon $B=-0.1 \mathrm{~m} \mathrm{~s}^{-2}$ isoline) at peak supercell stage.

\begin{tabular}{|c|c|c|c|c|}
\hline & LOW-25 & CTRL-0 & HIGH-25 & HIGH-40 \\
\hline Peak cold pool magnitude $\left(\mathrm{m} \mathrm{s}^{-2}\right)$ & -0.248 & -0.291 & -0.321 & -0.228 \\
\hline Peak cold pool depth (m) & 1250 & 2750 & 1750 & 750 \\
\hline
\end{tabular}




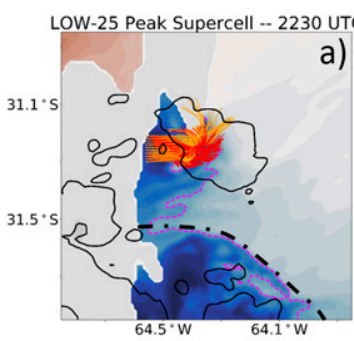

e) LoW-25

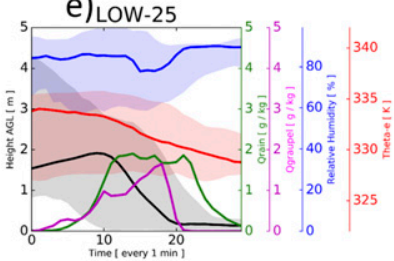

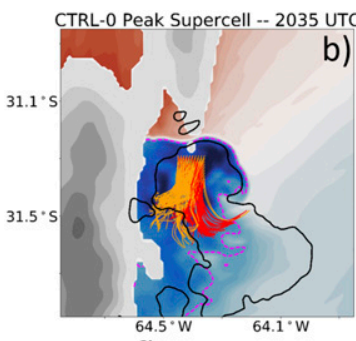

f) CTRL-0

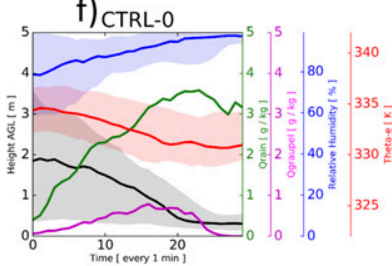

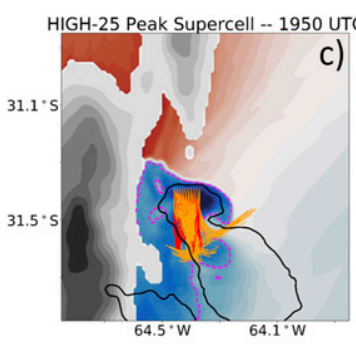

g) $)_{\text {IIGH-25 }}$

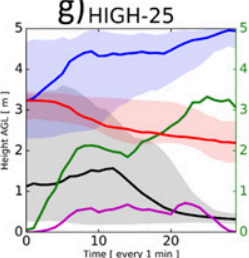

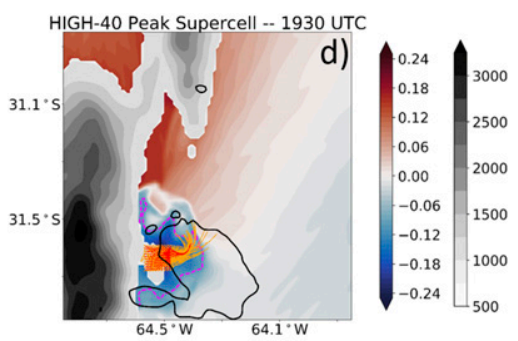

h) $\mathrm{HIGH}-40$

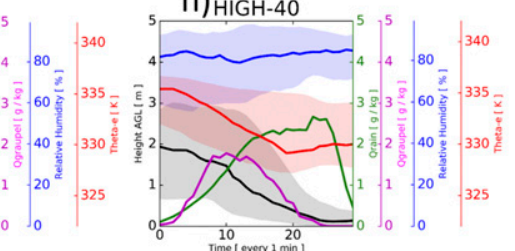

FIG. 19. $1 \mathrm{~km}$ WRF output at peak supercell time depicting: (a)-(d) $\sim 1 \mathrm{~km}$ thermal buoyancy (color shaded; $\mathrm{m} \mathrm{s}^{-2}$ ),$-0.1 \mathrm{~m} \mathrm{~s}^{-2}$ thermal buoyancy contour (magenta lines), $30 \mathrm{dBZ}$ lowest model level reflectivity contour (black lines), terrain height (shaded in gray every $250 \mathrm{~m}$ starting at $500 \mathrm{~m}$ ), horizontal parcel trajectory pathways for parcels terminating at peak cold pool locations at ground level (red lines) and slightly above (orange lines), and the approximate outflow boundary position (dot-dashed black line) from the frontal MCS in (a). (e)-(h) Time series of quantities from backward parcel trajectories over the lowest 10 model levels. Black lines are the median and shading are the 25th/75th percentiles of parcel height AGL $(\mathrm{km})$, red lines are the median and shading are the $25 \mathrm{th} / 75$ th percentiles of equivalent potential temperature $(\mathrm{K})$, blue lines are the median and shading are the $25 \mathrm{th} / 75$ th percentiles of $\mathrm{RH}(\%)$, green lines are the median values of rain mass mixing ratios $\left(\mathrm{g} \mathrm{kg}^{-1}\right)$, and magenta lines are the median values of graupel mass mixing ratios $\left(\mathrm{g} \mathrm{kg}^{-1}\right)$.

revealed direct and indirect effects on the convective evolution of this orographic supercell-to-MCS transition. Direct effects included terrain blocking of cold pools, leading to deeper cold pools (e.g., in higher terrain experiments). Indirect effects included changes in environmental conditions such as vertical wind shear and CAPE variations, which then affected storm morphology. Higher terrain height environments were characterized by stronger low-level and deep-layer vertical wind shear, higher LCLs, and lower magnitudes of MLCAPE (and vice versa for lower terrain experiments). CI was relatively earlier in higher terrain experiments and later in the lower terrain experiments, owing to enhanced low-level ascent from a standing mountain wave and increased upslope flow. Even when the underlying terrain was effectively reduced to a plateau (e.g., LOW-40 experiment), a supercell formed, although weaker. This supports the notion that the ambient environment in this case was conducive for the formation of supercells, regardless of terrain height. UCG into an MCS, however, only occurred when there was more substantial terrain height, with the "real" terrain configuration of the CTRL-0 experiment supporting the fastest UCG. The reduced blocking of cold pools and stronger/faster frontal MCS in lower terrain experiments and stronger deep-layer vertical wind shear and less MLCAPE in higher terrain experiments, help explain why when the terrain height of the SDC was deviated from its "real" configuration, that UCG rate was slowed relative to the control.
Parcel trajectories within the cold pools of the simulated supercells revealed that for the experiments with the strongest and deepest cold pools (CTRL-0 and HIGH-25 experiments), more air originated over the higher terrain to the west. The parcels that originated over the higher terrain were characterized by lower initial $\mathrm{RH}$, potentially supporting more enhanced diabatic microphysical cooling compared with parcels that originated over the lower terrain to the east. Decreases in equivalent potential temperature for parcels that terminated within the low-level cold pools of the peak supercells across all terrain experiments, however, showed similar reductions owing to diabatic latent cooling. The complicated 3D airflows in and around complex terrain revealed by the parcel trajectories examined here need further investigation across many more events and supported by additional numerical modeling simulations in order to disentangle the specific diabatic contributions to cold pool formation and specific properties. Future work should include computing and analyzing total integrated latent cooling along parcel trajectory pathways in order to more robustly determine the driving mechanisms for the aforementioned cold pool properties and formation.

While this study identified some important influences of terrain on the UCG process of orographic supercells for this particular event, many more UCG events near complex terrain need to be examined. Questions remain that motivate continued research into this topic, such as: 
1) Do all supercells initiated over complex terrain grow upscale faster/more readily than supercells initiated over flatter, more homogenous terrain? 2) Is it the direct influence (e.g., terrain blocking of cold pools) of terrain on supercells that matters most for UCG, or is it the indirect influence of terrain on the environment (e.g., variations in vertical wind shear/CAPE owing to terrain) which then affects supercell morphology? Or is it a combination of both? 3) Is there an "optimal" terrain height and/or configuration that leads to the most rapid UCG of orographic supercells? The copious observational data collected during both the Remote sensing of Electrification, Lightning, and Mesoscale/microscale Processes with Adaptive Ground Observations (RELAMPAGO; 2018) and Cloud, Aerosol, and Complex Terrain Interactions (CACTI; 2018-19) field experiments in north central Argentina, South America, will be leveraged to help answer these outstanding questions. Furthermore, high-resolution idealized numerical modeling experiments are underway to address these questions by systematically varying terrain, vertical wind shear, CAPE, among other variables, to analyze and further understand their effects on the orographic supercell-to-MCS UCG process.

Acknowledgments. The first author would like to thank Dr. Brian Jewett, Chuan-Chieh Chang, Geoff Marion, Benjamin Vega-Westhoff, and Tzu-shun Lin (University of Illinois at Urbana-Champaign; UIUC) for computing assistance, Tom Gowan (University of Utah) for use of his Python trajectory code (https:// github.com/tomgowan/trajectories), and Drs. John M. Peters (Naval Postgraduate School), Hugh Morrison (National Center for Atmospheric Research), and Michael Coniglio (National Severe Storms Laboratory) for fruitful discussions. Many thanks go to Dr. Bowen Pan (Texas A\&M University), Dr. Bruno Ribeiro (Centro de Previsão do Tempo e Estudos Climáticos), and Janice Mulholland for their extremely useful comments improving this manuscript. The authors would also like to thank the main editor, Dr. Daniel Kirshbaum, and three anonymous reviewers, for the extremely thought provoking and insightful comments and suggestions on this work. Computational resources were provided by the Computational and Information Systems Laboratory at the National Center for Atmospheric Research. Córdoba radar data were provided by Secretaría de Infraestructura y Política Hídrica, Ministerio del Interior, Obras Públicas y Vivienda of the Argentinean National Government framed within the Sistema Nacional de Radares Meteorológicos (SINARAME) Project. The SINARAME project is an Argentine effort to expand the radar network over the entire country.
Support for this work was made possible by National Science Foundation Grants AGS-1661799 for the first and second authors and AGS-1661800 for the third author.

\section{REFERENCES}

Anabor, V., D. J. Stensrud, and O. L. L. de Moraes, 2008: Serial upstream-propagating mesoscale convective system events over southeastern South America. Mon. Wea. Rev., 136, 3087 3105, https://doi.org/10.1175/2007MWR2334.1.

Bluestein, H. B., and M. L. Weisman, 2000: The interaction of numerically simulated supercells initiated along lines. Mon. Wea. Rev., 128, 3128-3149, https://doi.org/10.1175/ 1520-0493(2000)128<3128:TIONSS > 2.0.CO;2.

Bosart, L. F., A. Seimon, K. D. LaPenta, and M. J. Dickinson, 2006: Supercell tornadogenesis over complex terrain: The Great Barrington, Massachusetts, tornado on 29 May 1995. Wea. Forecasting, 21, 897-922, https://doi.org/10.1175/WAF957.1.

Bresson, E., V. Ducrocq, O. Nuissier, D. Ricard, and C. de Saint-Aubin, 2012: Idealized numerical simulations of quasi-stationary convective systems over the Northwestern Mediterranean complex terrain. Quart. J. Roy. Meteor. Soc., 138, 1751-1763, https://doi.org/10.1002/qj.1911.

Bryan, G. H., and R. Rotunno, 2014: The optimal state for gravity currents in shear. J. Atmos. Sci., 71, 448-468, https://doi.org/ 10.1175/JAS-D-13-0156.1.

— J. C. Wyngaard, and J. M. Fritsch, 2003: Resolution requirements for the simulation of deep moist convection. Mon. Wea. Rev., 131, 2394-2416, https://doi.org/10.1175/ 1520-0493(2003)131<2394:RRFTSO > 2.0.CO;2.

Coniglio, M. C., D. J. Stensrud, and L. J. Wicker, 2006: Effects of upper-level shear on the structure and maintenance of strong quasi-linear mesoscale convective systems. J. Atmos. Sci., 63 , 1231-1252, https://doi.org/10.1175/JAS3681.1.

_ J. Y. Hwang, and D. J. Stensrud, 2010: Environmental factors in the upscale growth and longevity of MCSs derived from Rapid Update Cycle analyses. Mon. Wea. Rev., 138, 35143539, https://doi.org/10.1175/2010MWR3233.1.

— S. F. Corfidi, and J. S. Kain, 2011: Environment and early evolution of the 8 May 2009 derecho-producing convective system. Mon. Wea. Rev., 139, 1083-1102, https://doi.org/ 10.1175/2010MWR3413.1.

Conway, J. W., H. E. Brooks, and K. D. Hondl, 1996: The 17 August 1994 Lahoma, OK supercell: Issues of tornadogenesis and bow echo formation. Preprints, 18th Conf. on Severe Local Storms, San Francisco, CA, Amer. Meteor. Soc., 52-56.

Dial, G. L., J. P. Racy, and R. L. Thompson, 2010: Short-term convective mode evolution along synoptic boundaries. Wea. Forecasting, 25, 1430-1446, https://doi.org/10.1175/ 2010WAF2222315.1.

Done, J., C. A. Davis, and M. Weisman, 2004: The next generation of NWP: Explicit forecasts of convection using the Weather Research and Forecasting (WRF) model. Atmos. Sci. Lett., 5, 110-117, https://doi.org/10.1002/asl.72.

Droegemeier, K. K., and R. B. Wilhelmson, 1987: Numerical simulation of thunderstorm outflow dynamics. Part I: Outflow sensitivity experiments and turbulence dynamics. J. Atmos. Sci., 44, 1180-1210, https://doi.org/10.1175/1520-0469(1987) 044<1180:NSOTOD $>2.0 . \mathrm{CO} ; 2$.

Dudhia, J., 1996: A multi-layer soil temperature model for MM5. Proc. Sixth PSU/NCAR Mesoscale Model Users' Workshop, 
Boulder, CO, PSU/NCAR, 49-50, http://www2.mmm.ucar.edu/ wrf/users/phys_refs/LAND_SURFACE/5_layer_thermal.pdf.

Finley, C. A., W. R. Cotton, and R. A. Pielke Sr., 2001: Numerical simulation of tornadogenesis in a high-precipitation supercell. Part I: Storm evolution and transition into a bow echo. J. Atmos. Sci., 58, 1597-1629, https://doi.org/10.1175/ 1520-0469(2001)058<1597:NSOTIA > 2.0.CO;2.

Geerts, B., Q. Miao, and J. C. Demko, 2008: Pressure perturbations and upslope flow over a heated, isolated mountain. Mon. Wea. Rev., 136, 4272-4288, https://doi.org/10.1175/ 2008MWR2546.1.

Gowan, T. M., and J. W. Steenburgh, 2018: Using idealized large-eddy simulations to understand the impact of downstream terrain on lake-effect snowfall. 18th Conf. on Mountain Meteorology, Santa Fe, NM, Amer. Meteor. Soc., 5.5, https://ams.confex.com/ams/18Mountain/webprogram/ Paper346052.html.

Hawblitzel, D. P., F. Zhang, Z. Meng, and C. A. Davis, 2007: Probabilistic evaluation of the dynamics and predictability of a mesoscale convective vortex of 10-13 June 2003. Mon. Wea. Rev., 135, 1544-1563, https://doi.org/10.1175/MWR3346.1.

Hong, S. Y., Y. Noh, and J. Dudhia, 2006: A new vertical diffusion package with an explicit treatment of entrainment processes. Mon. Wea. Rev., 134, 2318-2341, https://doi.org/ 10.1175/MWR3199.1.

Iacono, M. J., J. S. Delamere, E. J. Mlawer, M. W. Shephard, S. A. Clough, and W. D. Collins, 2008: Radiative forcing by longlived greenhouse gases: Calculations with the AER radiative transfer models. J. Geophys. Res., 113, D13103, https://doi.org/ 10.1029/2008JD009944.

Kain, J. S., and Coauthors, 2008: Some practical considerations regarding horizontal resolution in the first generation of operational convection-allowing NWP. Wea. Forecasting, 23, 931-952, https://doi.org/10.1175/WAF2007106.1.

Klimowski, B. A., M. R. Hjelmfelt, and M. J. Bunkers, 2004: Radar observations of the early evolution of bow echoes. Wea. Forecasting, 19, 727-734, https://doi.org/10.1175/ 1520-0434(2004)019<0727:ROOTEE $>2.0 . C O ; 2$

Laing, A. G., and J. M. Fritsch, 1997: The global population of mesoscale convective complexes. Quart. J. Roy. Meteor. Soc., 123, 389-405, https://doi.org/10.1002/qj.49712353807.

Mapes, B. E., 1993: Gregarious tropical convection. J. Atmos. Sci., 50, 2026-2037, https://doi.org/10.1175/1520-0469(1993) $050<2026: G T C>2.0 . C O ; 2$.

Marion, G. R., and R. J. Trapp, 2019: The dynamical coupling of convective updrafts, downdrafts, and cold pools in simulated supercell thunderstorms. J. Geophys. Res. Atmos., 124, 664 683, https://doi.org/10.1029/2018JD029055.

Markowski, P. M., and N. Dotzek, 2011: A numerical study of the effects of orography on supercells. Atmos. Res., 100, 457-478, https://doi.org/10.1016/j.atmosres.2010.12.027.

McAnelly, R. L., J. E. Nachamkin, W. R. Cotton, and M. E. Nicholls, 1997: Upscale evolution of MCSs: Doppler radar analysis and analytical investigation. Mon. Wea. Rev., 125, 1083-1110, https://doi.org/10.1175/1520-0493(1997)125<1083: UEOMDR $>2.0 . \mathrm{CO} ; 2$.

Miglietta, M. M., J. Mazon, and R. Rotunno, 2017: Numerical simulations of a tornadic supercell over the Mediterranean. Wea. Forecasting, 32, 1209-1226, https://doi.org/10.1175/ WAF-D-16-0223.1.

Miltenberger, A. K., S. Pfahl, and H. Wernli, 2013: An online trajectory module (version 1.0) for the nonhydrostatic numerical weather prediction model COSMO. Geosci.
Model Dev., 6, 1989-2004, https://doi.org/10.5194/gmd-61989-2013.

Moller, A. R., C. A. Doswell III, and R. W. Przybylinski, 1990: High precipitation supercells: A conceptual model and documentation. Preprints, 16th Conf. on Severe Local Storms, Kananaskis Park, AB, Canada, Amer. Meteor. Soc., 52-57.

Mulholland, J. P., S. W. Nesbitt, R. J. Trapp, K. L. Rasmussen, and P. V. Salio, 2018: Convective storm life cycle and environments near the Sierras de Cordoba, Argentina. Mon. Wea. Rev., 146, 2541-2557, https://doi.org/10.1175/MWR-D-18-0081.1.

Nesbitt, S. W., R. Cifelli, and S. A. Rutledge, 2006: Storm morphology and rainfall characteristics of TRMM precipitation features. Mon. Wea. Rev., 134, 2702-2721, https://doi.org/ 10.1175/MWR3200.1.

Nielsen, E. R., and R. S. Schumacher, 2018: Dynamical insights into extreme short-term precipitation associated with supercells and mesovortices. J. Atmos. Sci., 75, 2983-3009, https://doi.org/10.1175/JAS-D-17-0385.1.

—, G. R. Herman, R. C. Tournay, J. M. Peters, and R. S. Schumacher, 2015: Double impact: When both tornadoes and flash floods threaten the same place at the same time. Wea. Forecasting, 30, 1673-1693, https://doi.org/10.1175/WAF-D-15-0084.1.

Parker, M. D., 2018: External vs. self-organization of nocturnal MCSs from PECAN. 29th Conf. on Severe Local Storms, Stowe, VT, Amer. Meteor. Soc., 4.5, https://ams.confex.com/ ams/29SLS/meetingapp.cgi/Paper/348312.

Peters, J. M., and R. S. Schumacher, 2016: Dynamics governing a simulated mesoscale convective system with a training convective line. J. Atmos. Sci., 73, 2643-2664, https://doi.org/ 10.1175/JAS-D-15-0199.1.

— K. C. Eure, and R. S. Schumacher, 2017: Factors that drive MCS growth from supercells. 17th Conf. on Mesoscale Processes, San Diego, CA, Amer. Meteor. Soc., 9.6, https:// ams.confex.com/ams/17MESO/webprogram/Paper320248.html.

Phadtare, J., 2018: Role of Eastern Ghats orography and cold pool in an extreme rainfall event over Chennai on 1 December 2015. Mon. Wea. Rev., 146, 943-965, https://doi.org/10.1175/ MWR-D-16-0473.1.

Potvin, C., and M. Flora, 2015: Sensitivity of idealized supercell simulations to horizontal grid spacing: Implications for warnon-forecast. Mon. Wea. Rev., 143, 2998-3024, https://doi.org/ 10.1175/MWR-D-14-00416.1.

Rasmussen, K. L., M. D. Zuluaga, and R. A. Houze, 2014: Severe convection and lighting in subtropical South America. Geophys. Res. Lett., 41, 7359-7366, https://doi.org/10.1002/2014GL061767.

, M. M. Chaplin, M. D. Zuluaga, and R. A. Houze Jr., 2016: Contribution of extreme convective storms to rainfall in South America. J. Hydrometeor., 17, 353-367, https://doi.org/ 10.1175/JHM-D-15-0067.1.

Raymond, D. J., 1987: A forced gravity wave model of selforganized convection. J. Atmos. Sci., 44, 3528-3543, https:// doi.org/10.1175/1520-0469(1987)044<3528:AFGWMO> 2.0.CO;2.

Ribeiro, B. Z., and L. F. Bosart, 2018: Elevated mixed layers and associated severe thunderstorm environments in South and North America. Mon. Wea. Rev., 146, 3-28, https://doi.org/ 10.1175/MWR-D-17-0121.1.

Rotunno, R., J. B. Klemp, and M. L. Weisman, 1988: A theory for strong, long-lived squall lines. J. Atmos. Sci., 45, 463-485, https:// doi.org/10.1175/1520-0469(1988)045<0463:ATFSLL>2.0.CO;2.

Scheffknecht, P., S. Serafin, and V. Grubisic, 2017: A long-lived supercell over mountainous terrain. Quart. J. Roy. Meteor. Soc., 143, 2973-2986, https://doi.org/10.1002/qj.3127. 
Skamarock, W. C., and Coauthors, 2008: A description of the Advanced Research WRF version 3. NCAR Tech. Note NCAR/TN-475+STR, 113 pp., https://doi.org/10.5065/D68S4MVH.

Smith, B. T., R. L. Thompson, J. S. Grams, C. Broyles, and H. E. Brooks, 2012: Convective modes for significant severe thunderstorms in the contiguous United States. Part I: Storm classification and climatology. Wea. Forecasting, 27, 11141135, https://doi.org/10.1175/WAF-D-11-00115.1.

Soderholm, B., B. Ronalds, and D. J. Kirshbaum, 2014: The evolution of convective storms initiated by an isolated mountain ridge. Mon. Wea. Rev., 142, 1430-1451, https://doi.org/10.1175/ MWR-D-13-00280.1.

Thompson, G., P. R. Field, R. M. Rasmussen, and W. D. Hall, 2008: Explicit forecasts of winter precipitation using an improved bulk microphysics scheme. Part II: Implementation of a new snow parameterization. Mon. Wea. Rev., 136, 5095-5115, https://doi.org/10.1175/2008MWR2387.1.

Trapp, R. J., S. A. Tessendorf, E. S. Godfrey, and H. E. Brooks, 2005: Tornadoes from squall lines and bow echoes. Part I: Climatological distribution. Wea. Forecasting, 20, 23-34, https://doi.org/10.1175/WAF-835.1.

, G. R. Marion, and S. W. Nesbitt, 2017: The regulation of tornado intensity by updraft width. J. Atmos. Sci., 74, 41994211, https://doi.org/10.1175/JAS-D-16-0331.1.

Tripoli, G. J., and W. R. Cotton, 1989a: Numerical study of an observed orogenic mesoscale convective system. Part 1: Simulated genesis and comparison with observations. Mon. Wea. Rev., 117, 273-304, https://doi.org/10.1175/1520-0493(1989) $117<0273$ :NSOAOO $>2.0 . \mathrm{CO} ; 2$.

, and — 1989b: Numerical study of an observed orogenic mesoscale convective system. Part 2: Analysis of governing dynamics. Mon. Wea. Rev., 117, 305-328, https://doi.org/ 10.1175/1520-0493(1989)117<0305:NSOAOO > 2.0.CO;2.

Vera, C., and Coauthors, 2006: The South American low-level jet experiment. Bull. Amer. Meteor. Soc., 87, 63-78, https:// doi.org/10.1175/BAMS-87-1-63.

Verrelle, A., D. Ricard, and C. Lac, 2015: Sensitivity of highresolution idealized simulations of thunderstorms to horizontal resolution and turbulence parameterization. Quart. J. Roy. Meteor. Soc., 141, 433-448, https://doi.org/10.1002/ qj. 2363.

Warren, R. A., H. Richter, H. A. Ramsay, S. T. Siems, and M. J. Manton, 2017: Impact of variations in upper-level shear on simulated supercells. Mon. Wea. Rev., 145, 2659-2681, https:// doi.org/10.1175/MWR-D-16-0412.1.

Weisman, M. L., C. Evans, and L. Bosart, 2013: The 8 May 2009 superderecho: Analysis of a real-time explicit convective forecast. Wea. Forecasting, 28, 863-892, https://doi.org/ 10.1175/WAF-D-12-00023.1.

Wilson, J. W., N. A. Crook, C. K. Mueller, J. Sun, and M. Dixon, 1998: Nowcasting thunderstorms: A status report. Bull. Amer. Meteor. Soc., 79, 2079-2099, https://doi.org/10.1175/ 1520-0477(1998)079<2079:NTASR > 2.0.CO;2.

Xu, W., E. J. Zipser, Y.-L. Chen, C. Liu, Y.-C. Liou, W.-C. H. Lee, and B. J.-D. Jou, 2012: An orography-associated extreme rainfall event during TiMREX: Initiation, storm evolution, and maintenance. Mon. Wea. Rev., 140, 2555-2574, https:// doi.org/10.1175/MWR-D-11-00208.1.

Zipser, E. J., 1977: Mesoscale and convective-scale downdrafts as distinct components of squall-line circulation. Mon. Wea. Rev., 105, 1568-1589, https://doi.org/10.1175/ 1520-0493(1977)105<1568:MACDAD>2.0.CO;2. 